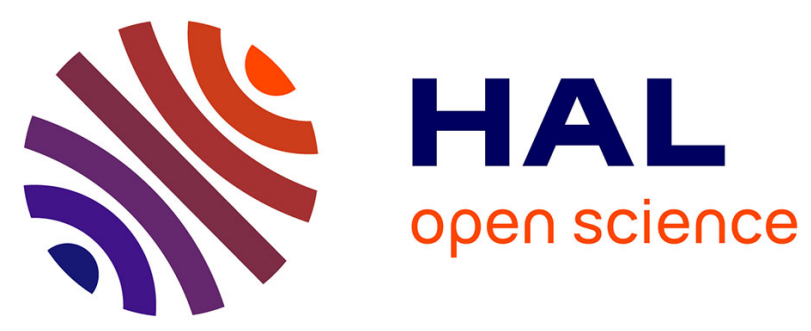

\title{
Drivers of the enhanced decline of land near-surface relative humidity to abrupt 4xCO2 in CNRM-CM6-1
}

Hervé Douville, Bertrand Decharme, C. Delire, J. Colin, E. Joetzjer, R. Roehrig, D. Saint-Martin, T. Oudar, R. Stchepounoff, A. Voldoire

\section{- To cite this version:}

Hervé Douville, Bertrand Decharme, C. Delire, J. Colin, E. Joetzjer, et al.. Drivers of the enhanced decline of land near-surface relative humidity to abrupt 4xCO2 in CNRM-CM6-1. Climate Dynamics, 2020, 55 (5-6), pp.1613-1629. 10.1007/s00382-020-05351-x . hal-03013962

\section{HAL Id: hal-03013962 https://hal.science/hal-03013962}

Submitted on 24 Nov 2020

HAL is a multi-disciplinary open access archive for the deposit and dissemination of scientific research documents, whether they are published or not. The documents may come from teaching and research institutions in France or abroad, or from public or private research centers.
L'archive ouverte pluridisciplinaire HAL, est destinée au dépôt et à la diffusion de documents scientifiques de niveau recherche, publiés ou non, émanant des établissements d'enseignement et de recherche français ou étrangers, des laboratoires publics ou privés. 
Drivers of the enhanced decline of land near-surface relative humidity to abrupt-4xCO 2 in CNRM-CM6-1

\section{H. Douville, B. Decharme, C. Delire, J. Colin, E. Joetzjer, R. Roehrig, D. Saint- Martin, T. Oudar, R. Stchepounoff, A.Voldoire}

10 Centre National de Recherches Météorologiques, Université de Toulouse, Météo-France, CNRS 42 Avenue Gaspard Coriolis, 31057 Toulouse France

15 Corresponding author address:

Dr. Hervé Douville

CNRM/GMGEC/AMACS, 42 avenue Gaspard Coriolis

31057 Toulouse Cedex 01, France

Email:herve.douville@meteo.fr

20 ORCID number : 0000-0002-6074-6467 


\begin{abstract}
25 Projected changes in near-surface relative humidity $(\mathrm{RH})$ remain highly model-dependent over land and may have been underestimated by the former generation global climate models. Here the focus in on the recent CNRM-CM6-1 model, which shows an enhanced land surface drying in response to quadrupled atmospheric $\mathrm{CO}_{2}$ compared to its CNRM-CM5 predecessor. Atmosphere-only experiments with prescribed sea surface temperature (SST) are used to decompose the simulated RH

30 changes into separate responses to uniform SST warming, pattern of SST anomalies, changes in seaice concentration, as well as direct radiative and physiological $\mathrm{CO}_{2}$ effects. Results show that the strong drying simulated by CNRM-CM6-1 is due to both fast $\mathrm{CO}_{2}$ effects and a SST-mediated response. The enhanced drying compared to CNRM-CM5 is partly due to the introduction of a physiological $\mathrm{CO}_{2}$ effect that was not accounted for in CNRM-CM5. The global ocean warming also

35 contributes to the RH decline over land, in reasonable agreement with the moisture advection mechanism proposed by earlier studies which however does not fully capture the contrasted RH response between the two CNRM models. The SST anomaly pattern is a significant driver of changes in $\mathrm{RH}$ humidity at the regional scale, which are partly explained by changes in atmospheric circulation. The improved land surface model may also contribute to a stronger soil moisture feedback

40 in CNRM-CM6-1, which can amplify the surface aridity induced by global warming and, thereby, lead to a non-linear response of RH.
\end{abstract}

Key words: climate change, relative humidity, land, drying, drivers 


\section{Introduction}

50 Under enhanced atmospheric $\mathrm{CO}_{2}$ concentration, relative humidity (RH) is expected to remain approximately constant on global and climatological time scales (Held and Soden, 2006). Yet, global climate models show regional disparities in projected changes in near surface $\mathrm{RH}$, especially over land where such changes may have policy-relevant impacts on human health (e.g., heat stress) and terrestrial ecosystems (e.g., wildfires). RH is also a key variable for understanding the projected landsea warming contrast (Byrne and O’Gorman, 2013), regional changes in surface evaporation (Laîné et al., 2014), land-ocean shifts in tropical precipitation (Lambert et al., 2017), and global changes in vegetation growth (Yuan et al., 2019).

According to the fifth assessment report (AR5) of the Intergovernmental Panel on Climate Change (IPCC), there is medium confidence that "reductions in near-surface RH over many land areas are

60 likely", mainly due to the larger warming rate projected over land than over ocean (Collins et al., 2013). Conversely, projected changes in RH were shown to contribute to the land amplification of global warming. A theory that assumes equal changes in equivalent potential temperature over land and ocean captures the projected land-sea warming contrast in the tropics (Byrne and O'Gorman, 2013). According to this theory, land surface RH changes and the land-sea contrast in the control

65 climate contribute equally to the tropical warming contrast, but the intermodel spread in the land-sea warming contrast is primarily linked to changes in land surface RH thereby emphasizing the need to better constrain them in climate projections.

Conceptual models, focusing on atmospheric moisture transport between the land and ocean, have been proposed to investigate the decrease in land surface $\mathrm{RH}$ as the climate warms (Byrne and O'Gorman, 2016; Chadwick et al., 2016). The simplest model assumes equal fractional increases in specific humidity over land and ocean and captures the main features of the projected changes in $\mathrm{RH}$ over land given the limited increase of RH over the oceans and the land-sea contrast in global warming. Yet, evapotranspiration was also found to contribute to the simulated decrease in RH over land, possibly due to the stomatal closure effect of increased atmospheric $\mathrm{CO}_{2}$ and thereby amplifying

75 the land surface warming (Byrne and O'Gorman, 2016). Land surface evapotranspiration can also be suppressed by the soil drying (Jung et al., 2010; Mueller and Seneviratne, 2014), which can also lead to a stronger land surface warming (Douville et al., 2016; Vogel et al., 2017). 
Based on both in situ observations (https://www.metoffice.gov.uk/hadobs/hadisdh/) and comprehensive European Centre for Medium-Range Weather Forecasts reanalyses (ECMWF)

80 reanalyses, a reduction in RH over low-latitude and midlatitude land areas was detected after 1998 (Simmons et al., 2010). The various data sets agreed well for both temperature and humidity variations for periods and places of overlap. Near-surface specific humidity was shown to vary similarly over land and sea, suggesting that the recent reduction in RH over land could be due to limited moisture supply from the oceans. This hypothesis was further supported by the simple

85 moisture transport model assuming equal fractional changes in specific humidity over land and ocean (Byrne and O'Gorman, 2018). The predictions of this analytical model were shown to be broadly consistent with the observed trends in land $\mathrm{RH}$ given the observed warming over ocean, despite considerable variability about the best-fit trend in land RH that could be related to other factors such as changes in atmospheric circulations and land-surface properties. The detected decline in land surface RH should be however considered with caution at the regional scale given the possible change in measurement methods and the contrasted multi-decadal trends which can be found between raw and homogeneized in situ observations (Freychet et al., 2020).

Post-AR5 studies (Douville and Plazzotta, 2017; Dunn et al., 2017) suggest that the apparent decrease in land surface RH was underestimated by most models from the fifth phase of the Coupled Model

95 Intercomparison Project (CMIP5). This observed drying was attributed to anthropogenic forcings and used to constrain the projected decline of near surface $\mathrm{RH}$ over the boreal summer mid-latitude continents, suggesting a systematic underestimation of the land surface drying by these models (Douville and Plazzotta, 2017). Interestingly, the CNRM-CM6-1 model (Voldoire et al., 2019) shows a realistic land surface drying when driven by observed SST (Fig. 1) and an enhanced response of 100 land surface $\mathrm{RH}$ to quadrupled atmospheric $\mathrm{CO}_{2}$ compared to the former CNRM-CM5 model (Voldoire et al., 2013) (Fig. 2). Globally averaged, this enhanced land surface drying is found all year round but is much more pronounced in boreal summer (Fig. 3a). It is related to an enhanced continental warming given the opposite changes in specific humidity which indicate a stronger moistening in CNRM-CM6-1 over both land (Fig. 3c) and sea (Fig. 3d).

105 The present study is aimed at better understanding the drivers of this boreal summer (June to September, hereafter JJAS) response of land surface RH, mainly using atmosphere-only experiments proposed by the Cloud Feedback Model Intercomparison Project (CFMIP) component of CMIP6 and already tested in a pilot study (Chadwick et al. 2017) with three atmospheric general circulation models (AGCMs) including the atmospheric component of CNRM-CM5. This pilot study revealed 110 that the so-called physiological $\mathrm{CO}_{2}$ effect, not accounted for in CNRM-CM5, may have a significant 
impact on tropical forest precipitation. There is indeed growing evidence that plants optimize their water use efficiency (WUE, i.e., the amount of $\mathrm{CO}_{2}$ absorbed by photosynthesis per amount of water lost by transpiration) by reducing the opening of their stomata under elevated atmospheric $\mathrm{CO}_{2}$ concentration. This physiological response can lead to decreased land surface RH as a result of reduced plant transpiration (Berg et al., 2016; Cao et al., 2010; Lemordant et al., 2018; Swann et al., 2016). The resulting drying and warming of the atmospheric boundary layer can also lead to a decrease in precipitation, at least over densely vegetated land areas (Richardson et al., 2018). Yet, this stomatal closure effect exhibit strong species specificity and can be partly offset by a $\mathrm{CO}_{2}$ fertilization effect (i.e., increased photosynthesis and vegetation density) so that the net physiological $\mathrm{CO}_{2}$ effect on land surface evapotranspiration and precipitation remains highly model-dependent.

Here, the focus is both on the understanding of the CNRM-CM6-1 near-surface RH response and on the comparison with CNRM-CM5. Note that the new CNRM-CM6-1 model includes a stomatal closure effect of atmospheric $\mathrm{CO}_{2}$ on plant transpiration (not accounted for in CNRM-CM5) but still has a prescribed vegetation phenology (Decharme et al., 2019b). The paper is structured as follows.

125 Section 2 highlights the contrasted response of CNRM-CM6-1 and CNRM-CM5 to an abrupt quadrupling of atmospheric $\mathrm{CO}_{2}$ and describes the various atmosphere-only experiments which are used in the present study. The breakdown of the JJAS RH response to abrupt-4xCO 2 into multiple contributions is shown in Section 3, with a particular focus on the physiological $\mathrm{CO}_{2}$ effect. Section 4 further explores the role of moisture advection in the land surface humidity response to sea surface warming, the potential influence of the mean state, and the linearity of the RH response to increased $\mathrm{CO}_{2}$. The main conclusions are summarized in Section 5 which also discusses the limitations and implications of the study and suggests a few prospects for further research.

\section{Models and experiment design}

CNRM-CM6-1 is the standard configuration of the CNRM global climate model which has recently contributed to the core experiments of CMIP6 (Eyring et al., 2016) as well as to many parallel intercomparisons such as the Cloud Feedback Model Intercomparison project (CFMIP, Webb et al., 2017). It is based on the ARPEGE-Climat v6.3 atmospheric general circulation model, the NEMO

140 v3.6 ocean general circulation model, the GELATO sea-ice model, as well as the SURFEX v8.0 landsurface modelling platform associated to the CTRIP v2 river routing scheme (Decharme et al., 
2019b). The atmospheric horizontal resolution is about $1.4^{\circ}$ and there are 91 vertical levels up to 0.01 $\mathrm{hPa}$, while the oceanic resolution is $1^{\circ}$ with a latitudinal refinement to $1 / 3^{\circ}$ at the equator and 75 vertical levels. In the continuation of the study, we will distinguish the coupled model, CNRM-CM61, from its land-atmosphere configuration which will be noted CNRM-AM6-1.

While all model components have been updated in CNRM-CM6-1 compared to CNRM-CM5 (Voldoire et al., 2019), a particular attention has been paid to the land surface physics. In CNRMCM5, the land surface was modeled trough the ISBA-TRIP system (Decharme and Douville, 2007) based on a three-layer soil hydrology and a simple one-layer snow scheme embedded in the SURFEX

1505.2 numerical platform. The plant transpiration was simulated via a simple Jarvis-type scheme (Jarvis, 1976) as a function of the LAI (Leaf Area Index), root zone water stress, and meteorological constraints (solar radiation, air temperature, saturation deficit). In CNRM-CM6-1, the new land surface system, ISBA-CTRIP (Decharme et al., 2019a), is embedded in the SURFEX 8.0 numerical platform where ISBA now explicitly solves the one-dimensional Fourier and Darcy laws throughout the soil and a multilayer snow model enables a separate water and energy budgets to be simulated for the soil and the snowpack. Plant transpiration is controlled by the stomatal conductance of leaves, which depends on carbon cycling in vegetation (Calvet et al., 1998) but the LAI phenology remains prescribed. This parameterization allows the model to simulate the stomatal closure effect of atmospheric $\mathrm{CO}_{2}$ on plant transpiration but not the fertilization effect on plant biomass.

160 A more comprehensive description of the model components and of their coupling can be found in Voldoire et al. (2019), as well as an evaluation of the model performance in present-day climate conditions and a brief overview of the model sensitivity to increasing $\mathrm{CO}_{2}$. A striking feature of CNRM-CM6-1 is the enhanced equilibrium climate sensitivity $\left(\mathrm{ECS}=4.9^{\circ} \mathrm{C}\right)$ compared to the former CNRM-CM5 model $\left(\mathrm{ECS}=3.3^{\circ} \mathrm{C}\right)$ involved in CMIP5. A detailed analysis of this enhanced climate 165 sensitivity highlights the key role of the convection scheme through an increase in the longwave tropical cloud feedback (Saint-Martin et al., personal communication). The demonstration partly relies on the implementation of an intermediate model configuration, CNRM-CM6-atm5 $\left(\mathrm{ECS}=3.4^{\circ} \mathrm{C}\right)$, in which the atmospheric component of CNRM-CM6-1 was replaced by the one from CNRM-CM5 (which also differs from CNRM-CM6-1 by its ocean, sea-ice and land surface 170 components).

The three pairs of piControl and abrupt-4xCO 2 experiments achieved with CNRM-CM6-1, CNRMCM5 and CNRM-CM6-atm5 are also the starting point of the present study. Looking back at the climatological annual cycle of RH, CNRM-CM6-atm5 is very close to CNRM-CM5 over the global 
ocean (Fig. 3b). In contrast, the hybrid model shows different piControl and abrupt-4xC02

175 climatologies over land (Fig. 3a) and an intermediate summer drying compared to CNRM-CM5 and CNRM-CM6-1. The results suggest that ocean RH is primarily controlled by the atmospheric component of the coupled model, while land RH is partly controlled by the land surface model and its coupling with the atmosphere. A striking difference between CNRM-CM6-1 and CNRM-CM5 is the enhanced land-sea contrast in RH which is already found under preindustrial climate but is further enhanced in the abrupt- $4 \mathrm{xCO}_{2}$ experiment.

Focusing on the JJAS season, Fig. 4a-c compare the geographical patterns of the RH response in the three model configurations. The patterns are scaled by the annual mean global warming to account for the stronger climate sensitivity in CNRM-CM6-1 compared to CNRM-CM5 and CNRM-CM6atm5. The land surface drying is more than twice in CNRM-CM6-1 $\left(-0.58 \% /{ }^{\circ} \mathrm{C}\right)$ versus CNRM-CM5

$185\left(-0.24 \% /{ }^{\circ} \mathrm{C}\right)$, and does not show exactly the same geographical patterns as revealed by their limited spatial correlation $(\mathrm{ACC}=0.65)$. The scaled $\mathrm{RH}$ response is much stronger in CNRM-CM6-atm5 ($0.50 \% /{ }^{\circ} \mathrm{C}$ ) compared to CNRM-CM5 despite their similar ECS. The stronger ECS in CNRM-CM61 explains why the scaled response is only slightly lower in CNRM-CM6-atm5, unlike the unscaled response shown in Fig. 3a. Regarding the pattern of the JJAS land surface drying, the hybrid model 190 configuration shares common features with both CNRM-CM5 and CNRM-CM6-1, but also regional differences (e.g., stronger Amazonian drying, weaker Mediterranean drying) thereby suggesting a complex interplay between the atmosphere and the other model components. In other words, the enhanced RH decline found in CNRM-CM6-1 is only partially explained by its stronger climate sensitivity compared to CNRM-CM5 and is not dominated by the atmospheric component given the 195 distinct response in CNRM-CM6-atm5 versus CNRM-CM5.

In order to go one step further, the present study takes advantage of CFMIP experiments performed with CNRM-AM6-1 (cf. Table 1). A first pair of time-slice simulations, piSST and a4SSTice-4xCO aims at replicating the piControl and abrupt $-4 \mathrm{xCO}_{2}$ coupled experiments and was also performed with CNRM-AM5. This is done by prescribing the same atmospheric $\mathrm{CO}_{2}$ concentrations but also monthly 200 mean annually varying oceanic boundary conditions derived from the SST and sea-ice concentration (SIC) simulated from year 111 to 140 in piControl and abrupt- $4 \mathrm{xCO}_{2}$ respectively. Such AGCM experiments were shown to capture the main features of the precipitation response to abrupt- $4 \mathrm{xCO}_{2}$ in three CMIP5 coupled models including CNRM-CM5 (Chadwick et al., 2017). Fig. 4d shows that they also allow CNRM-AM6-1 to reproduce the pattern $(\mathrm{ACC}=0.97)$ and overall magnitude ($2050.56 \% /{ }^{\circ} \mathrm{C}$ ) of the $\mathrm{RH}$ response simulated by CNRM-CM6-1. 
The other AGCM experiments are parallel 30-year integrations (after spin-up) aiming at splitting the atmospheric response to abrupt- $4 \mathrm{xCO}_{2}$ into separate responses to different aspects of $\mathrm{CO}_{2}$ forcing and related ocean warming (uniform SST warming, patterned SST change, sea-ice change, radiative and/or physiological $\mathrm{CO}_{2}$ effect, cf. Table 1). The total response can be first decomposed as follows :

210 a4SSTice- $4 \mathrm{xCO}_{2}-$ piSST $=\left(\mathrm{a} 4 \mathrm{SSTice}-4 \mathrm{xCO}_{2}-\mathrm{a} 4 \mathrm{SSTice}\right)+(\mathrm{a} 4 \mathrm{SSTice}-$ piSST-pxK $)+($ piSST-pxK $-\operatorname{piSST})(1)$

where the three right-hand terms represent the direct $\mathrm{CO}_{2}$ effect, the SST anomaly pattern and SIC effects, and the uniform SST warming effect respectively.

It should be here emphasized that the CFMIP experiment design (Webb et al., 2017) differs slightly

215 from the early pilot study using CNRM-AM5 (Chadwick et al., 2017). In the pilot study, the sea-ice effect was ignored (in the two other AGCMs) or included in the SST anomaly pattern of CNRM-AM5 in which the monthly mean SST were prescribed over both open and sea-ice covered ocean surfaces. In other words, the polar amplification of the global ocean warming due to the sea-ice retreat was entirely included in the SST anomaly pattern for CNRM-AM5, while it is also accounted for in the 220 uniform SST warming effect in CNRM-AM6-1 since the polar surface warming is partly due to dynamical effects such as the advection of warmer and moister air masses from the mid-latitudes. Looking at the annual mean near-surface air temperature (not shown), the so-called SIC and SST anomaly pattern effect leads to a global cooling of $-0.62^{\circ} \mathrm{C}$ in $\mathrm{CNRM}-\mathrm{AM} 5$ versus a global warming of $+0.39^{\circ} \mathrm{C}$ in CNRM-AM6-1. Such a difference should be kept in mind when interpreting the results

225 of the AGCM experiments. Note also that the uniform and patterned SST warming were rescaled to match a $+4^{\circ} \mathrm{C}$ global and annual mean average in the pilot study, so that a reverse scaling factor is here applied to compare CNRM-AM5 and CNRM-CM5.

In CNRM-AM6-1, the $\mathrm{CO}_{2}$ effect can be further deconstructed into its physiological versus radiative component under preindustrial SST/SIC as follows:

piSST-4xCO $2-$ piSST $=\left(\right.$ piSST-4xCO $2-$ piSST- $\left.4 \mathrm{xCO}_{2}-\mathrm{rad}\right)+\left(\right.$ piSST $-4 \mathrm{xCO}_{2}-\mathrm{rad}-$ piSST $)(2)$

and it will be shown that the total $\mathrm{CO}_{2}$ effect does not depend too much on the mean climate (cf. section 3.2). While the CFMIP experiment design assumes the additivity of the radiative and physiological $\mathrm{CO}_{2}$ effects, it should be emphasized that this hypothesis cannot be verified since the physiological effect is estimated as a residual in the first right-hand term of Eq. (2). 
235 An ultimate time-slice atmospheric simulation was proposed by CFMIP in order to assess the role of the mean state SST on the model response through a comparison with the amip core experiment driven by the 1979-2014 observed monthly mean SST and SIC boundary conditions (section 4.2). This additional experiment (amip-a4SST-4xCO 2 , cf. Table 1) is the same as amip, but with a quadrupled $\mathrm{CO}_{2}$ and a patterned SST warming applied on top of the amip SSTs. This climatological

240 monthly SST pattern is the same as in the a4SST experiments, but the observed interannual variability from the amip experiment is preserved. Since the projected decline in SIC is not accounted for in the amip-a4SST-4 $\mathrm{xCO}_{2}$ experiment, it has been here decided to run an additional a4SST-4 $\mathrm{xCO}_{2}$ with preindustrial SIC in order to ensure a clean comparison of the response to $\mathrm{CO}_{2}$ quadrupling and related SST warming on top of present-day versus preindustrial SST boundary conditions.

245 Table 2 summarizes how each component of the total response to abrupt- $4 \mathrm{xCO}_{2}$ are calculated. The statistical significance of all contributions will be assessed using a two-sided t-test at the $5 \%$ level suitable for multiple testing (Wilks, 2016).

\section{Breakdown of the JJAS response to abrupt-4xCO2}

\subsection{Comparison between CNRM-AM6-1 and CNRM-AM5}

Fig. 5 and 6 show the Eq. (1) decomposition of the boreal summer RH response to abrupt $-4 \mathrm{xCO}_{2}$ in CNRM-AM6-1 and CNRM-AM5 respectively. Starting with CNRM-AM6-1, the global land averaged decrease in $\mathrm{RH}(-3.68 \%)$ is primarily due to the $\mathrm{CO}_{2}$ effect $(-2.26 \%)$ and to the uniform SST

255 warming $(-1.78 \%)$. This uniform warming drives a significant drying in the tropics and subtropics, but an increased RH in the northern latitudes (Fig. 5b). It explains about half of the spatial variability of the total response simulated over land. In contrast, the response to $\mathrm{CO}_{2}$ (Fig. 5d) shows an enhanced drying in the northern extratropics, a less homogeneous response in the tropics, and a limited correlation with the total response. The global contribution of the SIC and SST anomaly pattern is 260 much weaker but also shows significant regional responses.

Moving to CNRM-AM5, the global land averaged decrease in RH is only of $-1.65 \%$ (Fig. 4a) and the breakdown is different. There is a dominant contribution of the uniform SST warming, which is strengthened by the contribution of the radiative $\mathrm{CO}_{2}$ effect but partly offset by the response to the SST anomaly pattern. As explained in Section 2, this stronger contribution of the SIC and SST 
265 anomaly pattern is partly an artifact of the experiment design. Since the polar amplification of the global ocean warming is here included in the SST anomaly pattern effect, this leads to a relative cooling of the tropical and mid-latitude prescribed SST which can partly offset the RH response to the uniform SST warming effect. This explanation is supported by the relative symmetry of the geographical patterns shown in Fig. $6 \mathrm{~b}$ and c. A more valuable comparison is the sum of the RH

270 responses to the uniform SST warming and to the SIC and SST anomaly pattern. This non- $\mathrm{CO}_{2}$ effect leads to a global land surface drying of $-1.42 \%$ in CNRM-AM6-1 versus $-0.34 \%$ in CNRM-AM5, and therefore explains 53\% of the enhanced RH decline in CNRM-AM6-1 (-3.68\%) compared to CNRM-AM5 (-1.65\%).

Changes in low-level atmospheric circulation have been superimposed on JJAS RH anomalies in both

275 Fig. 5 and 6. They suggest that atmospheric moisture transport play a key role in regional RH changes. Some features are apparently robust such as the strong drying driven by the uniform SST warming over Sahel in both CNRM-AM6-1 and CNRM-AM5, partly as a response to a weakening of the West African monsoon circulation (Fig. 5b and 6b). In contrast, the response to the SST anomaly pattern shows a significant drying signal over India in CNRM-AM6-1, which is associated with a weakening of the South Asian monsoon but is not found in CNRM-AM5 (Fig. 5c and 6c).

To sum up, the direct and SST-mediated $\mathrm{CO}_{2}$ effects contribute equally to the enhanced $\mathrm{RH}$ decline in CNRM-CM6-1 compared to CNRM-CM5. The stronger drying due to the direct $\mathrm{CO}_{2}$ effect is potentially related to the introduction of the physiological effect on plant transpiration (Section 3.2). The response to the uniform SST warming will be further discussed in Section 4.1. The SIC and SST

285 pattern leads to a contrasted response between CNRM-AM5 and CNRM-AM6.1, which is partly an artifact of differences in the experiment design. This pattern has a small global signature in CNRMAM6-1, but significant positive and negative effects at the regional scale. A further decomposition of this pattern effect (not shown) indicates that the SIC effect is negligible and that the RH response is dominated by the tropical SST anomalies and related circulation changes.

\subsection{Influence of the physiological $\mathrm{CO}_{2}$ effect}

The influence of the stomatal closure $\mathrm{CO}_{2}$ effect can be assessed in CNRM-AM6-1 by using Eq. (2) and further splitting the fast response to $\mathrm{CO}_{2}$ into a radiative versus physiological component (Fig. 7). Such a decomposition is only possible under preindustrial climate conditions (Fig. 7b) given the 295 CFMIP experiment design. The total $\mathrm{CO}_{2}$ effect is however relatively close between warm (Fig. 7a) 
and cold (Fig. 7b) climates. The physiological effect (Fig. 7c) drives a widespread decrease in RH over the tropical, temperate and boreal forests. It is associated with reduced evapotranspiration (not shown) and dominates the $\mathrm{RH}$ response to the direct $\mathrm{CO}_{2}$ effect over land. Note that the radiativeonly CO2 effect in CNRM-AM6 (Fig. 7d, -0.15\%) is however weaker than in CNRM-AM5 (Fig. 6d, $-1.30 \%$ ). The additional physiological $\mathrm{CO}_{2}$ effect therefore contributes to the stronger land surface RH decline found in Fig. 5d compared to Fig. 6d, but this additional contribution is partly offset by a weaker radiative-only effect so that the fast response to $\mathrm{CO}_{2}$ does not explain the whole additional land surface drying found in CNRM-AM6-1 (Fig. 5a) compared to CNRM-AM5 (Fig. 6a). The much weaker radiative-only $\mathrm{CO}_{2}$ effect found in CNRM-AM6-1 may have multiple causes, including a

305 contrasted adjustment of low-level cloudiness and of temperature and humidity profiles in the planetary boundary layer. Yet, it may also raise the question of the potential interaction between the radiative and physiological $\mathrm{CO}_{2}$ effects which is not addressed by the current CFMIP experiment design.

Globally speaking, the land surface drying due to the physiological $\mathrm{CO}_{2}$ effect (-2.22\%) accounts for $60 \%$ of the total drying (-3.68\%) found in CNRM-AM6-1. The model contrast in the total direct $\mathrm{CO}_{2}$ effect represents $47 \%$ of the enhanced RH decline in CNRM-AM6-1 versus CNRM-AM5, in line with the previously estimated $53 \%$ contribution of the non- $\mathrm{CO}_{2}$ effects. It should be however emphasized that the physiological $\mathrm{CO}_{2}$ effect simulated in CNRM-CM6-1/AM6-1 may represent an extreme scenario in which the $\mathrm{CO}_{2}$ fertilization effect is ignored and the vegetation density (leaf area 315 index) is fixed at a present-day climatology (Decharme et al., 2019b). The fertilization effect is accounted for in the Earth System configuration of the CNRM model (Séférian et al., 2019), which however did not participate to CFMIP and is not considered in the present study.

\section{Discussion}

\subsection{Influence of land-sea contrast in specific humidity}

Byrne and O'Gorman (2016) developed a conceptual box model, involving atmospheric moisture transport between the land and ocean, to investigate the overall decline in land RH as the climate warms. The box model was applied to CMIP5 general circulation models and was found to capture

325 many of the features of the projected changes in land humidity. The simplest version of the box model 
ignores changes in atmospheric circulation and surface evapotranspiration. It just gives equal fractional increases in specific humidity, q, over land and sea:

$$
\left(\mathrm{q}_{1,2}-\mathrm{q}_{1,1}\right) / \mathrm{q}_{1,1}=\left(\mathrm{q}_{\mathrm{s}, 2}-\mathrm{q}_{\mathrm{s}, 1}\right) / \mathrm{q}_{\mathrm{s}, 1} \quad \Rightarrow \quad \mathrm{q}_{1,2}=\left(\mathrm{q}_{\mathrm{s}, 2} / \mathrm{q}^{*} \mathrm{~s}, 1\right) \cdot \mathrm{q}_{1,1}
$$

where subscripts 1 and s denote land and sea and subscripts 1 and 2 denote control and perturbed climates respectively. Here $\mathrm{q}^{*}$ denotes the ocean moisture source for each land grid point and is simply estimated as the seasonal and zonal mean of ocean surface $q$ at the same latitude.

In this model, future q over land is therefore determined by scaling the present-day pattern of land $\mathrm{q}$ by the fractional increase in the oceanic moisture source. This simple scaling was shown to agree well with the projected land surface specific humidity, at least much better than the Clausius-

335 Clapeyron scaling which assumes a constant RH and overestimates the projected increase in q over land (Chadwick et al., 2016). It implies a global decrease in land RH given the greater warming over land than ocean and the overall modest change in ocean RH. It also implies a stronger increase in $\mathrm{q}$ over land in CNRM-CM6-1, given the enhanced $\mathrm{q}_{\mathrm{s}, 2} / \mathrm{q}_{\mathrm{s}, 1}$ ocean ratio suggested by Fig. $3 \mathrm{~d}$.

Eq. (4) has been here applied to the JJAS mean climatology of specific humidity simulated in our

340 AGCM experiments. The focus is on the response to the uniform SST warming given the neglected role of changes in atmospheric circulation and surface evapotranspiration (which have been shown to contribute to the response to SST anomaly pattern and $\mathrm{CO}_{2}$ effects respectively). Both CNRM-AM5 (Fig. 8a) and CNRM-AM6-1 (Fig. 8b) show a maximum increase in q over the tropical ocean, but with regional differences over land (Fig. 8g). The simple scaling model is able to capture the main

345 features of the AGCM response over land (Fig. 8b and e), but is not accurate enough to understand the regional differences between CNRM-AM5 and CNRM-AM6-1 (Fig. 8h). The only exception is the Sahel region where the weaker increase in q found in CNRM-AM6-1 is partly reproduced by the simple scaling (in line with the difference in moisture advection implied by the contrasted low-level wind climatologies between the two AGCMs). The departures between the AGCM and simple scaling

350 results (Fig. 8c and f) illustrate the limitations of the simple advection model which does not account for changes in atmospheric circulation and land surface evapotranspiration.

Fig. 9 compares again the JJAS RH responses to uniform SST warming in CNRM-AM5 and CNRMAM6-1 (Fig. 9a and d). Note that the global land average decrease in RH is not the same as in Fig. $5 \mathrm{~b}$ and Fig. $6 \mathrm{~b}$ respectively since the focus is here between $60^{\circ} \mathrm{S}$ and $60^{\circ} \mathrm{N}$. The main reason is that 355 the simple advection model does not account for snow-covered surfaces and that we derive RH from the simple model estimate of q (and from the AGCM near-surface temperature and surface pressure 
outputs) using an empirical formulation of saturation specific humidity (Murray, 1967) which is less suitable in cold climates. The results show that the simple scaling captures the main features of the RH changes simulated by both CNRM AGCMs when a uniform SST warming is prescribed. The obtained geographical patterns (Fig. 9b and e) show a strong similarity with the AGCM patterns, and so does the predicted difference (Fig. 9h) between the two AGCMs. Yet, the simple moisture advection model (Fig. 9h) does not explain the stronger tropical and mid-latitude drying (-0.81\%) found in CNRM-AM6-1 compared to CNRM-CM5 (Fig. 9g). This result is mostly due to a widespread and overall strong underestimation of the CNRM-AM6-1 drying, which may suggest a stronger role for the land-atmosphere coupling in this model whereby the land surface decrease in RH can be amplified by a more positive soil moisture feedback (Berg et al., 2016). This hypothesis will be further explored in Section 4.3.

\subsection{Mean state influence on model sensitivity}

370 Another key question of CFMIP (Webb et al., 2017) is to explore to what extent climate projections depend on coupled model SST biases. While the SST biases of the piControl experiment cannot be assessed accurately given the limited observational record of preindustrial SST, the role of the mean state SST on the CNRM-AM6-1 response to abrupt-4xCO 2 can be assessed through the comparison of two pairs of experiments, aSST- $4 \mathrm{xCO}_{2}$ versus piSST on the one hand, amip-a4SST-4 $\mathrm{xCO}_{2}$ versus

375 amip on the other hand (cf. Table 1). Fig. 10 shows the two pairs of RH anomalies between the perturbed and control climates (Fig. 10c-d), as well as the difference between the two control and two perturbed simulations (Fig. 10a-b). The geographical pattern of the RH response does not much depend on the mean control climate.

Yet, the overall land surface drying is slightly weaker when the $\mathrm{CO}_{2}$ and SST perturbations are 380 applied onto present-day rather than preindustrial conditions. Such a difference may have several plausible explanations. For instance, the stomatal closure effect introduced in CNRM-CM6-1 is quite complex (Decharme et al., 2019b; Joetzjer et al., 2015) and is sensitive to the absolute atmospheric $\mathrm{CO}_{2}$ concentration which is higher in amip than in piSST. A more basic explanation is a possible sensitivity to the control climate. Fig. 10a shows that the amip simulation is globally drier than the 385 piSST simulation. This is for instance obvious over North America and Australia which show a weaker drying when the $\mathrm{CO}_{2}$ and SST perturbations are applied onto present-day rather than preindustrial climate conditions (Fig. 10c-d). 
A dry bias in the control climate may therefore limit the land surface drying due to climate change. Such a result is consistent with a soil moisture limitation of land surface evapotranspiration but may not apply where and when surface evapotranspiration is instead limited by the incoming solar radiation. This hypothesis is further supported by the fact that the mean state dependence vanishes in boreal winter (not shown), in line with an overall weaker soil moisture control on land surface evapotranspiration in the Northern Hemisphere. The mean-state dependence can also contribute to the enhanced drying found in CNRM-CM6-1 given its globally improved soil moisture climatology compared to CNRM-CM5 which showed a widespread dry bias over the northern Hemisphere continents (cf. Fig. 9 in Decharme et al., 2019).

\subsection{Second versus first doubling of atmospheric $\mathrm{CO}_{2}$}

Before moving to the conclusion of the study, let's come back to the coupled CNRM-CM6-1 model

400 and explore the linearity of the $\mathrm{RH}$ response as a function of the $\mathrm{CO}_{2}$ increase. For this purpose, we make use of the abrupt-2xCO 2 coupled experiment proposed within CFMIP (Webb et al., 2017). Fig. 11 shows the JJAS RH response to abrupt-2 $\mathrm{xCO}_{2}$ (Fig. 11a), abrupt-4xCO 2 (Fig. 11b), as well as the difference between the response to the second versus first $\mathrm{CO}_{2}$ doubling (Fig. 11c). The results emphasize a strong non-linearity with the second $\mathrm{CO}_{2}$ doubling leading to a much stronger drying

405 than the first one over many regions including Amazonia, South Africa, Australia, part of the US, Europe and northern Asia. These regions also show an increased land surface warming for the second $\mathrm{CO}_{2}$ doubling (not shown), thereby suggesting a regional effect whereby increased warming is associated with enhanced drying.

Globally averaged over land, the drying due to the second $\mathrm{CO}_{2}$ doubling is almost twice the response 410 to the first one. This result is again consistent with a significant summertime soil moisture feedback in CNRM-CM6-1. This hypothesis is further supported by Fig. 11d-f showing the response of the evaporative fraction (i.e., the ratio of latent heat flux to the sum of latent and sensible heat flux at the surface). A 50\% value in the piControl climatology (black solid line) highlights the areas where the latent heat represents less half of the total heat flux at the surface over land. The similar geographical

415 patterns found in Fig. 11c and Fig. 11f suggest that the non-linear additive drying found in CNRMCM6-1 is associated with a non-linear response of the evaporative fraction (EF). This response implies a strong coupling beween soil moisture and near-surface humidity. If there was no change in soil moisture, the near-surface drying should on the contrary drive an increase in the actual 
evapotranspiration and, therefore, in EF.

420 The overall soil drying is evidenced by the relative changes in total soil moisture (Fig.11g-h). In most subtropical and midlatitude areas, the decrease in EF can be explained by a corresponding decrease in soil moisture. Yet, there are some exceptions in the northern latitudes where EF can increase despite decreasing total soil moisture. In these high-latitude regions, surface evapotranspiration is mostly limited by energy rather than soil moisture and the drying is not necessarily driven by the atmospheric

425 water demand. It could be rather explained by a non-linear deepening of the permafrost summertime active layer associated with a non-linear response of the springtime snow cover (not shown).

Overall, the results suggest a positive land-atmosphere feedback whereby decreased RH over land is likely to increase not only the atmospheric water demand but also the actual land surface evapotranspiration, and thereby deplete soil moisture and further decrease RH. Yet, for a stronger

430 radiative forcing (4 times instead of 2 times $\mathrm{CO}_{2}$ ) or after a longer period (e.g., the drying is still increasing after year 150 in the abrupt- $4 \mathrm{xCO}_{2}$ experiment), the enhanced soil moisture depletion can ultimately lead to a reduced surface evapotranspiration, a decreased evaporative fraction, a stronger increase in land surface temperature, an enhanced land-sea warming contrast and a further decrease in RH through the ocean moisture advection mechanism. This feedback seems to be stronger than the

435 mean-state dependence highlighted in Section 4.2. It deserves further analyses and a careful evaluation, since it may imply an enhanced long-term soil moisture depletion in the absence of climate change mitigation, at least at the regional scale.

\section{Conclusions}

440 The aim of the study was to better understand the contrasted land surface RH response to abrupt4xCO 2 in CNRM-CM6-1 versus CNRM-CM5, as well as to illustrate the interest of the CFMIP Tier 2 AGCM experiments proposed within CFMIP. The results show that such atmosphere-only experiments are able to capture the coupled model response to increased $\mathrm{CO}_{2}$ and are therefore useful for understanding the multiple drivers of this atmospheric response. The breakdown of the RH

445 response indicates that the enhanced summertime land surface drying found in CNRM-CM6-1 compared to CNRM-CM5 is due to both the introduction of a physiological $\mathrm{CO}_{2}$ effect and to a SSTmediated effect.

While the enhanced drying simulated by CNRM-CM6-1 is therefore not due to its greater ECS (cf. 
Fig. 4), the $\mathrm{CO}_{2}$ stomatal closure effect introduced in this model does not necessarily contradict the "warmer is drier" paradigm (Sherwood and Fu, 2014) claiming that the evaporative demand increases faster than precipitation over land. The stomatal closure effect increases the near-surface warming and drying over land and, thereby, strengthens the atmospheric demand (in coupled models, but not in off-line land surface models which may therefore overestimate the possible decoupling between the atmosphere and the land surface) and also leads to a soil moisture decline (cf. Fig.11ghi, although

455 the soil drying is even more obvious when focusing on the top layers, not shown). The response of other agro-ecological aridity indices may however lead to different conclusions (Roderick et al., 2015) and could deserve parallel analyses using the same CFMIP framework. Such analyses would also need to consider the $\mathrm{CO}_{2}$ fertilization effect which is not accounted for in CNRM-CM6-1 and could partly offset the $\mathrm{CO}_{2}$ stomatal closure effect.

460 The present study also suggests that a simple moisture advection model captures many features of the land surface air humidity response to global warming in both CNRM-CM5 and CNRM-CM6-1, as well as some regional contrasts between both model versions. Yet, this simple scaling is not sufficient to explain the overall stronger drying in CNRM-CM6-1. The relevance of changes in land surface evapotranspiration and large-scale atmospheric circulation for understanding regional changes in land

$465 \mathrm{RH}$ is therefore confirmed, and is only partly related to the direct $\mathrm{CO}_{2}$ effect and to the SST anomaly pattern effect. The projected land surface drying is sensitive to both land surface biases (given the expected mean state soil moisture impact on the soil moisture response) and land surface feedbacks (that may induce an enhanced drying in many regions in CNRM-CM6-1), which are not accounted for in the simple conceptual model.

470 A deeper evaluation and understanding of the land surface water budget and of its coupling with the atmosphere is therefore needed for improving the reliability of RH and land-sea warming contrast projections. The participation of other global modelling centers to CFMIP may be also useful to assess the robustness of our results about the relative role of direct versus SST-mediated $\mathrm{CO}_{2}$ effects on projected changes in the atmosphere and at the land surface. The limited role of sea-ice may be here

475 an artifact of the experiment design and should be further investigated in fully coupled experiments. Similarly, the CFMIP design assumes no land surface influence on SST temperature, which is a severe assumption that deserves further attention, for instance in the framework of LS3MIP (Van Den Hurk et al., 2016). Finally, it could be also interesting to replicate the CFMIP experiment design to deconstruct the abrupt $-2 \mathrm{xCO}_{2}$ response of the coupled models and, thereby, better understand the 480 drivers of the non-linear response when shifting from $2 \mathrm{xCO}_{2}$ to $4 \mathrm{xCO}_{2}$. 
Acknowledgements : The authors would like to thank all people at CNRM and CERFACS who were involved in the development of the CNRM-CM5 and CNRM-CM6-1 models. Thanks are also due to

485 Sophie Tyteca and Richard Stchepounoff for the preparation of the SST and SIC boundary conditions of the AGCM experiments with CNRM-CM5 and CNRM-CM6-1 respectively. The CNRM-CM6-1 model outputs from the CMIP6 DECK and CFMIP experiments can be downloaded from the ESGF. 


\section{References :}

490

Berg, A. M., Findell, K., Lintner, B. R., Giannini, A., Seneviratne, S. I., van den Hurk, B., et al. (2016). Land-atmosphere feedbacks amplify aridity increase over land under global warming. Nat. Clim. Chang. 6, 869-874.

Byrne, M. P., and O'Gorman, P. A. (2013). Link between land-ocean warming contrast and surface relative humidities in simulations with coupled climate models. Geophys. Res. Lett. doi:10.1002/grl.50971.

Byrne, M. P., and O'Gorman, P. A. (2016). Understanding decreases in land relative humidity with global warming: conceptual model and $\{\mathrm{G}\}\{\mathrm{C}\}\{\mathrm{M}\}$ simulations. J. Clim. 29, 9045-9061.

Byrne, M. P., and O'Gorman, P. A. (2018). Trends in continental temperature and humidity directly linked to ocean warming. Proc. Natl. Acad. Sci. 115, 4863-4868. doi:10.1073/pnas.1722312115.

Calvet, J.-C., Noilhan, J., Roujean, J.-L. L., Bessemoulin, P., Cabelguenne, M., Olioso, A., et al. (1998). An interactive vegetation SVAT model tested against data from six contrasting sites. Agric. For. Meteorol. 92, 73-95. doi:10.1016/S0168-1923(98)00091-4.

505 Cao, L., Bala, G., Caldeira, K., Nemani, R., and Ban-Weiss, G. (2010). Importance of carbon dioxide physiological forcing to future climate change. Proc. Natl. Acad. Sci. U. S. A. 107, 9513-9518. doi:10.1073/pnas.0913000107.

Chadwick, R., Douville, H., and Skinner, C. B. (2017). Timeslice experiments for understanding regional climate projections: applications to the tropical hydrological cycle and European winter circulation. Clim. Dyn. 49, 3011-3029. doi:10.1007/s00382-016-3488-6.

Chadwick, R., Good, P., and Willett, K. M. (2016). A simple moisture advection model of specific humidity change over land in response to $\{\mathrm{S}\}\{\mathrm{S}\}\{\mathrm{T}\}$ warming. J. Clim. 29, 7613-7632.

Collins, M., Knutti, R., Arblaster, J. M., Dufresne, J. L., Fichefet, T., Friedlingstein, P., et al. (2013). "Long-term Climate Change: Projections, Commitments and Irreversibility Pages 1029 to 1076," in Climate Change 2013 - The Physical Science Basis, ed. Intergovernmental Panel on Climate Change (Cambridge: Cambridge University Press), 1029-1136. 
doi:10.1017/CBO9781107415324.024.

Decharme, B., Delire, C., Minvielle, M., Colin, J., Vergnes, J., Alias, A., et al. (2019a). Recent Changes in the ISBA-CTRIP Land Surface System for Use in the CNRM-CM6 Climate Model and in Global Off-Line Hydrological Applications. J. Adv. Model. Earth Syst. 11, 1207-1252. doi:10.1029/2018MS001545.

Decharme, B., Delire, C., Minvielle, M., Colin, J., Vergnes, J. P., Alias, A., et al. (2019b). Recent Changes in the ISBA-CTRIP Land Surface System for Use in the CNRM-CM6 Climate Model and in Global Off-Line Hydrological Applications. J. Adv. Model. Earth Syst., 0-2. doi:10.1029/2018MS001545.

Decharme, B., and Douville, H. (2007). Global validation of the ISBA sub-grid hydrology. Clim. Dyn. 29. doi:10.1007/s00382-006-0216-7.

Douville, H., Colin, J., Krug, E., Cattiaux, J., and Thao, S. (2016). Midlatitude daily summer temperatures reshaped by soil moisture under climate change. Geophys. Res. Lett. 43, 812818. doi:10.1002/2015GL066222.

Douville, H., and Plazzotta, M. (2017). Midlatitude Summer Drying: An Underestimated Threat in CMIP5 Models? Geophys. Res. Lett. 44, 9967-9975. doi:10.1002/2017GL075353.

Dunn, R. J. H., Willett, K. M., Ciavarella, A., and Stott, P. A. (2017). Comparison of land surface humidity between observations and CMIP5 models. Earth Syst. Dyn. 8, 719-747. doi:10.5194/esd-8-719-2017.

Freychet, N., Tett, S. F. B., Yan, Z., and Li, Z. (2020). Underestimated Change of Wet-Bulb Temperatures Over East and South China. Geophys. Res. Lett. 47, 1-7. doi:10.1029/2019GL086140.

Held, I. M., and Soden, B. J. (2006). Robust responses of the hydrologic cycle to global warming. $J$. Clim. 19, 5686-5699. doi:10.1175/JCLI3990.1.

Joetzjer, E., Delire, C., Douville, H., Ciais, P., Decharme, B., Carrer, D., et al. (2015). Improving the ISBA\&lt;sub\&gt;CC\&lt;/sub\&gt; land surface model simulation of water and carbon fluxes and stocks over the Amazon forest. Geosci. Model Dev. 8, 1709-1727. doi:10.5194/gmd-81709-2015. 
545 Jung, M., Reichstein, M., Ciais, P., Seneviratne, S. I., Sheffield, J., Goulden, M. L., et al. (2010). Recent decline in the global land evapotranspiration trend due to limited moisture supply. Nature 467, 951-954. doi:10.1038/nature09396.

Laîné, A., Nakamura, H., Nishii, K., Miyasaka, T., La`^liné, A., Nakamura, H., et al. (2014). A diagnostic study of future evaporation changes projected in CMIP5 climate models. Clim. Dyn. 42, 2745-2761. doi:10.1007/s00382-014-2087-7.

Lambert, F. H., Ferraro, A. J., and Chadwick, R. (2017). Land-ocean shifts in tropical precipitation linked to surface temperature and humidity change. J. Clim. 30, 4527-4545. doi:10.1175/JCLID-16-0649.1.

Lemordant, L., Gentine, P., Swann, A. S., Cook, B. I., and Scheff, J. (2018). Critical impact of 555 vegetation physiology on the continental hydrologic cycle in response to increasing CO 2. Proc. Natl. Acad. Sci. 0, 201720712. doi:10.1073/pnas.1720712115.

Mueller, B., and Seneviratne, S. I. (2014). Systematic land climate and evapotranspiration biases in CMIP5 simulations. Geophys. Res. Lett. 41, 128-134. doi:10.1002/2013GL058055.

Murray, F. W. (1967). On the Computation of Saturation Vapor Pressure. J. Appl. Meteorol. 6, 203560 204. doi:10.1175/1520-0450(1967)006<0203:otcosv>2.0.co;2.

Richardson, T. B., Forster, P. M., Andrews, T., Boucher, O., Faluvegi, G., Fläschner, D., et al. (2018). Carbon Dioxide Physiological Forcing Dominates Projected Eastern Amazonian Drying. Geophys. Res. Lett. doi:10.1002/2017GL076520.

Roderick, M. L., Greve, P., and Farquhar, G. D. (2015). On the assessment of aridity with changes 565 in atmospheric $<\mathrm{scp}>\mathrm{CO}</ \mathrm{scp}>$ 2. Water Resour. Res. 51, 5450-5463. doi:10.1002/2015WR017031.

Séférian, R., Nabat, P., Michou, M., Saint-Martin, D., Voldoire, A., Colin, J., et al. (2019). Evaluation of CNRM Earth-System model, CNRM-ESM 2-1: role of Earth system processes in present-day and future climate. doi:10.1029/2019MS001791.

570 Sherwood, S., and Fu, Q. (2014). A drier future? Science (80-. ). 343, 737-739. doi:10.1126/science.1247620.

Simmons, A. J., Willett, K. M., Jones, P. D., Thorne, P. W., and Dee, D. P. (2010). Low-frequency 
variations in surface atmospheric humidity, temperature, and precipitation: Inferences from reanalyses and monthly gridded observational data sets. J. Geophys. Res. Atmos. 115, 1-21. doi:10.1029/2009JD012442.

Swann, A. L. S., Hoffman, F. M., Koven, C. D., and Randerson, J. T. (2016). Plant responses to increasing $\mathrm{CO} 2$ reduce estimates of climate impacts on drought severity. Proc. Natl. Acad. Sci. 113, 10019-10024. doi:10.1073/pnas.1604581113.

Van Den Hurk, B., Kim, H., Krinner, G., Seneviratne, S. I., Derksen, C., Oki, T., et al. (2016). LS3MIP (v1.0) contribution to CMIP6: The Land Surface, Snow and Soil moisture Model Intercomparison Project - Aims, setup and expected outcome. Geosci. Model Dev. 9, 28092832. doi:10.5194/gmd-9-2809-2016.

Vogel, M. M., Orth, R., Cheruy, F., Hagemann, S., Lorenz, R., van den Hurk, B. J. J. M., et al. (2017). Regional amplification of projected changes in extreme temperatures strongly controlled by soil moisture-temperature feedbacks. Geophys. Res. Lett. 44, 1511-1519. doi:10.1002/2016GL071235.

Voldoire, A., Saint-Martin, D., Sénési, S., Decharme, B., Alias, A., Chevallier, M., et al. (2019). Evaluation of CMIP6 DECK Experiments With CNRM-CM6-1. J. Adv. Model. Earth Syst., 03. doi:10.1029/2019MS001683.

590 Voldoire, A., Sanchez-Gomez, E., Salas y Mélia, D., Decharme, B., Cassou, C., Sénési, S., et al. (2013). The CNRM-CM5.1 global climate model: Description and basic evaluation. Clim. Dyn. 40, 2091-2121. doi:10.1007/s00382-011-1259-y.

Webb, M. J., Andrews, T., Bodas-Salcedo, A., Bony, S., Bretherton, C. S., Chadwick, R., et al. (2017). The Cloud Feedback Model Intercomparison Project (CFMIP) contribution to CMIP6. Geosci. Model Dev. 10, 359-384. doi:10.5194/gmd-10-359-2017.

Wilks, D. S. (2016). "The stippling shows statistically significant grid points": How research results are routinely overstated and overinterpreted, and what to do about it. Bull. Am. Meteorol. Soc. 97, 2263-2273. doi:10.1175/BAMS-D-15-00267.1.

Yuan, W., Zheng, Y., Piao, S., Ciais, P., Lombardozzi, D., Wang, Y., et al. (2019). Increased 600 atmospheric vapor pressure deficit reduces global vegetation growth. Sci. Adv. 5, 1-13. doi:10.1126/sciadv.aax1396. 


\section{List of Tables :}

Table 1: Summary of the AGCM timeslice experiments. All experiments are 30-year integrations after spin-up except amip and amip-a4SST-4xCO 2 (36-year long integrations after spin-up).

Table 2: Calculation of the different components of the model response to abrupt-4xCO 2 . Note that the respective contributions of SIC change and SST anomaly pattern will not shown in the present study since their merged contribution is strongly dominated by the SST effect.

\begin{tabular}{|c|c|c|}
\hline $\begin{array}{l}\text { Name of } \\
\text { experiment }\end{array}$ & $\begin{array}{c}\text { Monthly mean annually varying SST and SIC } \\
\text { boundary conditions }\end{array}$ & $\mathrm{CO}_{2}$ forcing \\
\hline piSST & Years $111-140$ of piControl & Preindustrial $\left(1 \mathrm{xCO}_{2}\right)$ \\
\hline piSST-pxK & $\begin{array}{l}\text { As piSST + uniform SST anomaly computed as the } \\
\text { climatological global mean difference between years } \\
111-140 \text { of abrupt- } 4 \mathrm{xCO}_{2} \text { and piControl }\end{array}$ & preindustrial \\
\hline piSST- $4 \mathrm{xCO}_{2}$ & As piSST & $\begin{array}{c}4 \mathrm{xCO}_{2} \text { seen by radiation } \\
\text { and vegetation }\end{array}$ \\
\hline piSST-4xCO 2 -rad & As piSST & $4 \mathrm{xCO}_{2}$ seen by radiation \\
\hline a4SSTice & Years $111-140$ of abrupt- $4 \mathrm{xCO}_{2}$ & preindustrial \\
\hline a4SSTice- $4 \mathrm{xCO}_{2}$ & As a4SSTice & $\begin{array}{l}4 \mathrm{xCO}_{2} \text { seen by radiation } \\
\text { and vegetation }\end{array}$ \\
\hline a4SST & $\begin{array}{l}\text { As a4SSTice but with sea-ice concentration from years } \\
\qquad 111-140 \text { of piControl }\end{array}$ & preindustrial \\
\hline $\mathrm{a} 4 \mathrm{SST}-4 \mathrm{xCO}_{2}$ & As a4SST & $\begin{array}{c}4 \mathrm{xCO}_{2} \text { seen by radiation } \\
\text { and vegetation }\end{array}$ \\
\hline amip & Observed 1979-2014 monthly mean SST and SIC & present-day \\
\hline $\begin{array}{l}\operatorname{amip}-\mathrm{a} 4 \mathrm{SST}- \\
4 \mathrm{xCO}_{2}\end{array}$ & $\begin{array}{l}\text { As amip + climatological patterned SST anomalies } \\
\text { calculated as the difference between years 111-140 of } \\
\text { abrupt- } 4 \mathrm{xCO}_{2} \text { and piControl }\end{array}$ & $\begin{array}{l}4 \times \text { present-day seen by } \\
\text { radiation and vegetation }\end{array}$ \\
\hline
\end{tabular}

610

Table 1: Summary of the AGCM timeslice experiments. All experiments are 30-year integrations after spin-up except amip and amip-a4SST-4xCO 2 (36-year long integrations after spin-up). 


\begin{tabular}{|c|c|}
\hline Component & Calculation \\
\hline All forcings & a4SSTice- $4 \mathrm{xCO}_{2}-$ piSST \\
\hline Uniform SST warming & piSST-pxK - piSST \\
\hline SST anomaly pattern and SIC change & a4SSTice - piSST-pxK \\
\hline SIC change & a4SSTice - a4SST \\
\hline SST anomaly pattern & a4SST - piSST-pxK \\
\hline Radiative and physiological $\mathrm{CO}_{2}$ effects & $\begin{array}{l}\text { a4SSTice- } 4 \mathrm{xCO}_{2}-\mathrm{a} 4 \mathrm{SSTice} \\
\text { or piSST- } 4 \mathrm{xCO}_{2}-\text { piSST }\end{array}$ \\
\hline Physiological $\mathrm{CO}_{2}$ effect & piSST-4xCO $2-$ piSST-4xCO 2 -rad \\
\hline
\end{tabular}

615

Table 2: Calculation of the different components of the model response to abrupt-4xCO 2 . Note that the respective contributions of SIC change and SST anomaly pattern will not shown in the present study since their merged contribution is strongly dominated by the SST effect. 


\section{List of Figures :}

Figure 1: Timeseries of RH anomalies (\%) relative to the 1995-2014 climatology: a) Annual mean anomalies averaged over global land areas except Antarctica, b) JJAS mean anomalies averaged over the northern midlatitude land areas. The solid green line represents the ensemble mean of 10 extended

625 AMIP integrations of the atmospheric component of CNRM-CM6-1 driven by observed monthly mean SST and SIC, with the 95\% confidence interval in light green shading. The black line represents the anomalies in the ERA-Interim reanalysis. $\mathrm{R}$ denotes the time correlation between the ensemble mean and ERA-Interim anomalies.

Figure 2: Annual mean RH response (\%) to abrupt-4xCO 2 in a) CNRM-CM6-1, b) CNRM-CM5. The

630 model responses are averaged over years $111-140$ of the piControl and abrupt- $4 \mathrm{xCO}_{2}$ experiments. Stippling highlights areas where the differences are significant at the 5\% level. The black solid line is the 50\\% isoline of the piControl climatology. GLD denotes the average global land difference and ACC denotes the spatial continental pattern correlation with the differences shown in panel a).

Figure 3: Climatological annual cycle of near-surface a,b) relative humidity (\%) and c,d) specific

635 humidity $\left(\mathrm{g} / \mathrm{kg}\right.$ ) averaged over 30 years (years 111-140) in the piControl and abrupt-4xCO $\mathrm{CO}_{2}$ simulations with CNRM-CM5, CNRM-CM6-atm5 and CRNM-CM6-1 respectively, averaged over global land areas except Antarctica (a,c), global ocean areas except sea-ice covered surfaces (b,d). CNRM-CM6-atm5 is an intermediate model version in which the atmospheric component of CNRMCM6-1 has been replaced by the one from CNRM-CM5.

640 Figure 4: JJAS mean scaled RH response $\left(\% /{ }^{\circ} \mathrm{C}\right)$ to abrupt $-4 \mathrm{xCO}_{2}$ in a) $\mathrm{CNRM-CM6-1,} \mathrm{b)} \mathrm{CNRM-}$ CM5, c) the atmospheric component of CNRM-CM6-1, and d) CNRM-CM6-atm5. The response is scaled by the annual and global mean near-surface warming simulated by each model. The AOGCM responses are averaged over years 111-140 of the corresponding piControl and abrupt-4xCO experiments, while the AGCM response is averaged using 30-year timeslice simulations aimed at

645 capturing the response of CNRM-CM6-1 (cf. Table 1). Stippling highlights areas where the differences are significant at the 5\% level. The black solid line is the $50 \%$ isoline of the piControl climatology. GLD denotes the average global land difference and ACC denotes the spatial continental pattern correlation with the differences shown in panel a).

Figure 5: Breakdown of the JJAS mean RH response (\%) to abrupt-4xCO $\mathrm{X}_{2}$ in $\mathrm{CNRM-CM6-1} \mathrm{using}$ 650 pairs of atmosphere-only timeslice experiments (cf. Tables 1 and 2): a) total AGCM response, b) response to uniform SST warming, c) response to SST and SIC anomaly pattern, and d) response to 
$\mathrm{CO}_{2}$. All AGCM responses are averaged over 30 years. Stippling highlights areas where the differences are significant at the $5 \%$ level. Vectors represent the wind response $(\mathrm{m} / \mathrm{s})$ at $850 \mathrm{hPa}$. GLD denotes the average global land RH difference and ACC denotes the spatial continental pattern 655 correlation with the RH differences shown in panel a).

Figure 6: Same as Fig. 5, but for the breakdown of the JJAS mean RH response (\%) and $850 \mathrm{hPa}$ wind response $(\mathrm{m} / \mathrm{s})$ to abrupt-4xCO $\mathrm{x}_{2}$ in CNRM-CM5.

Figure 7: Breakdown of the JJAS mean RH response (\%) to $\mathrm{CO}_{2}$ in CNRM-CM6-1 using pairs of atmosphere-only timeslice experiments (cf. Tables 1 and 2): a) total $\mathrm{CO}_{2}$ effect under warm climate 660 (abrupt-4xCO 2 SST), b) total $\mathrm{CO}_{2}$ effect under control climate (piControl SST), c) Physiological $\mathrm{CO}_{2}$ effect under control climate, and d) Radiative $\mathrm{CO}_{2}$ effect under control climate. By experiment design $\mathrm{b}=\mathrm{c}+\mathrm{d}$. All AGCM responses are averaged over 30 years. Stippling highlights areas where the differences are significant at the 5\% level. Vectors represent the wind response $(\mathrm{m} / \mathrm{s})$ at $850 \mathrm{hPa}$. GLD denotes the average global land RH difference and ACC denotes the spatial continental pattern

665 correlation with the RH differences shown in panel a).

Figure 8: Changes in JJAS specific humidity (g/kg) due to uniform SST warming a,d) as simulated by the CNRM-CM5 and CNRM-CM6-1 AGCMs respectively (piSST-pxK minus piSST), and b,e) as predicted from a simple advection model based on the AGCM specific response over ocean only (cf. equation 4). Also shown are c) (a)-(b); f) (d)-(e); g) (d)-(a); h) (e)-(b); i) (f)-(c). The piSST JJAS

670 low-level ( $850 \mathrm{hPa})$ wind climatology is superimposed in b) and e) and the difference (e)-(b) is superimposed in $\mathrm{h}$ ).

Figure 9: Same as Fig. 8 but for changes in JJAS relative humidity (\%). In panels b) and c) relative humidity is estimated from specific humidity as shown in Fig. 8, using the empirical formulation by Murray (1967) and the AGCM temperature and surface pressure simulated in piSST and piSST-pxK.

675 Figure 10: Differences in JJAS relative humidity (\%) between: a) amip and piSST, b) amip-a4SST$4 \mathrm{xCO}_{2}$ and a4SST-4xCO 2 , c) amip-a4SST-4xCO 2 and amip, d) a4SST-4 $\mathrm{xCO}_{2}$ and piSST. Stippling highlights areas where the differences are significant at the 5\% level. GLD denotes the average global land RH difference and ACC denotes the spatial continental pattern correlation between the differences shown in panels c) and d) respectively.

680 Figure 11: Differences in JJAS a-c) relative humidity (\%), d-f) evaporative fraction (\%), g-i) total soil moisture (\%) between: a,d,g) abrupt-2xCO 2 and piControl, b,e,h) abrupt-4xCO 2 and piControl, c,f,i) 
second minus first $\mathrm{CO}_{2}$ doubling. Stippling in (a) and (b) highlights areas where the differences are significant at the 5\% level. GLD denotes the average global land RH difference. The black solid line denotes the $50 \%$ isoline and $1000 \mathrm{~kg} / \mathrm{m}^{2}$ of the piControl climatology in a-f) and g-i) respectively.

(a) Annual mean RH anomalies averaged over global land north of $60^{\circ} \mathrm{S}$

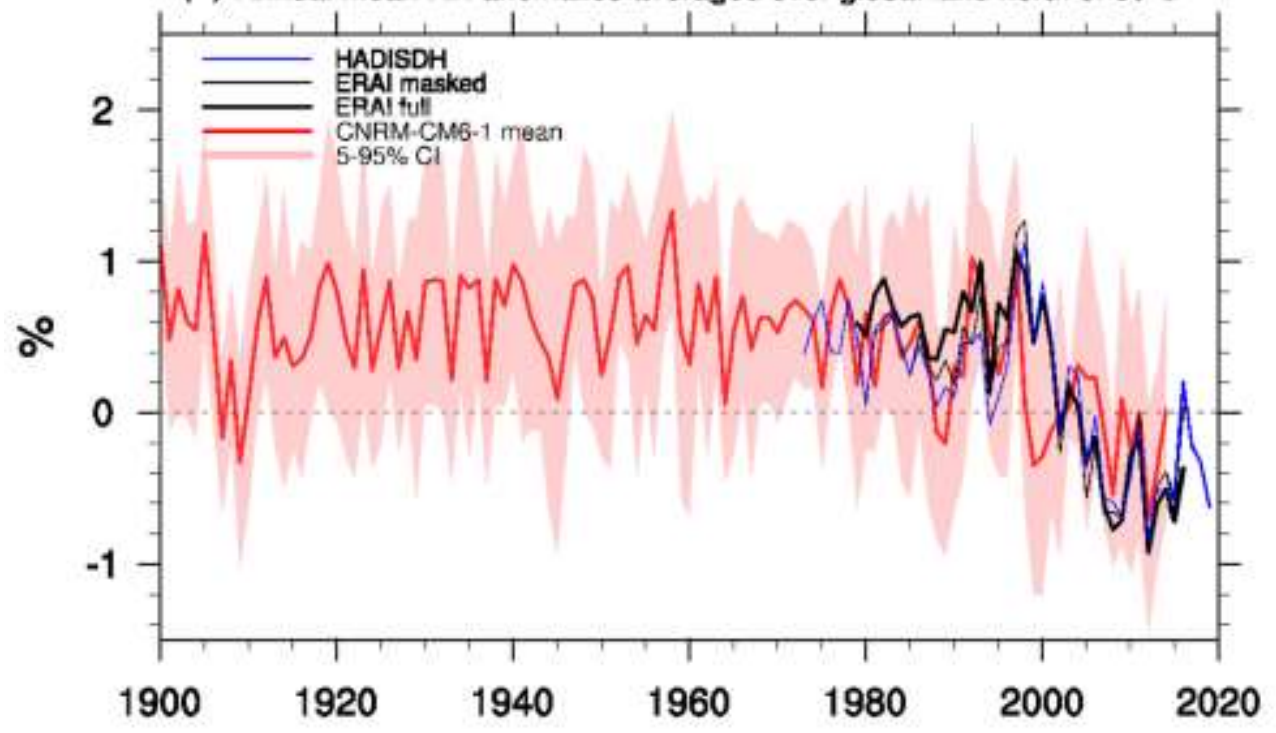

(b) JJAS mean RH anomalies averaged over northern midlatitude land

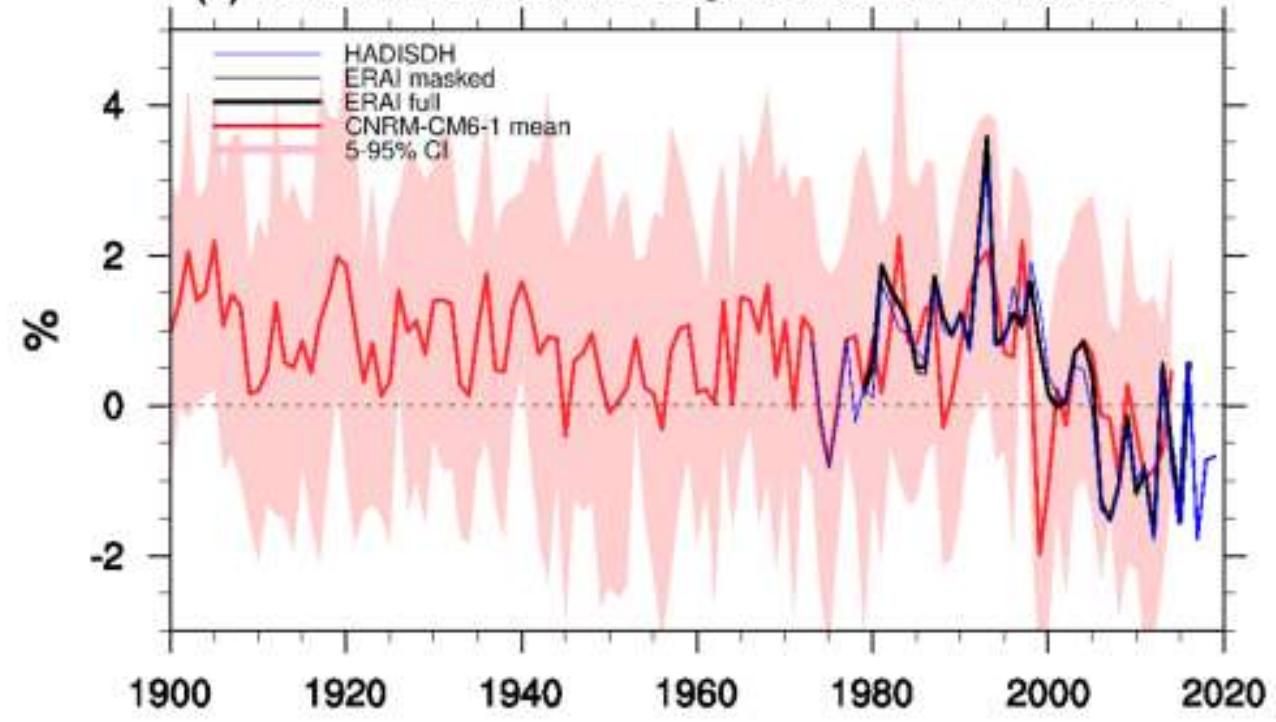

Figure 1 
Annual mean $\mathrm{RH}$ response to abrupt $4 \times \mathrm{CO} 2$
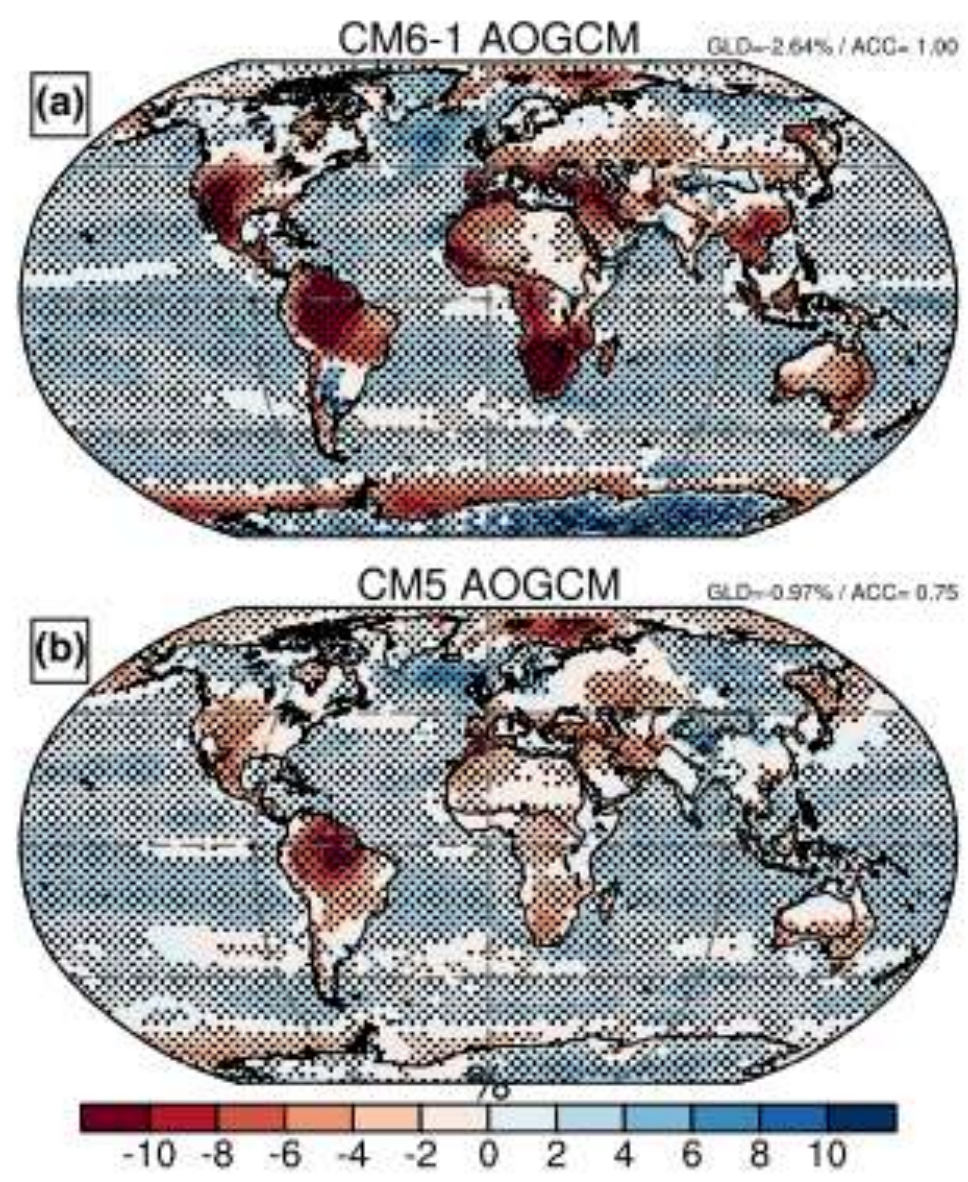

Figure 2 
(a) Climatological annual cycle of $\mathrm{RH}$ over Global Land north of $60^{\circ} \mathrm{S}$ [60S-90N, $\left.180 \mathrm{~W}-180 \mathrm{E}\right]$

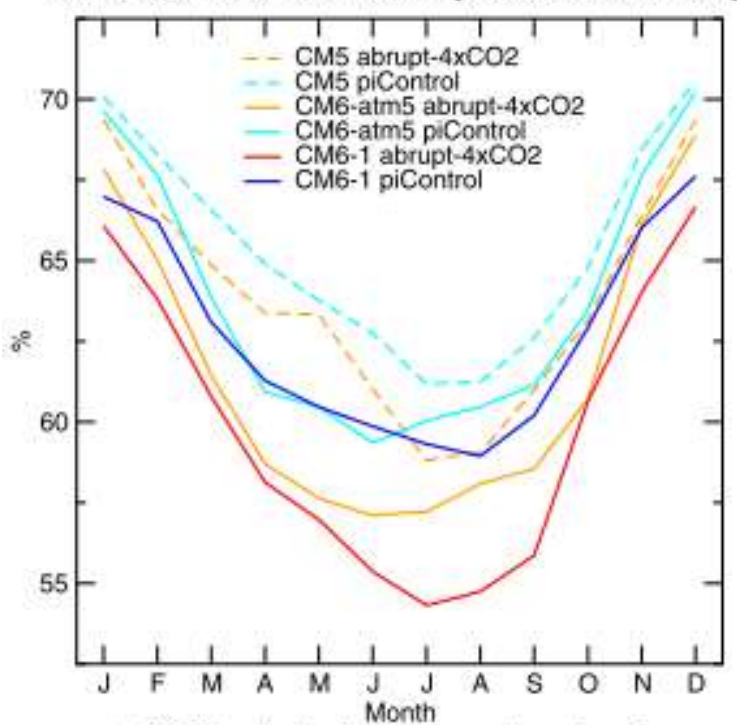

(c) Climatological annual cycle of $q$ over Global Land north of $60^{\circ} \mathrm{S}$ [60S-90N,180W-180E]

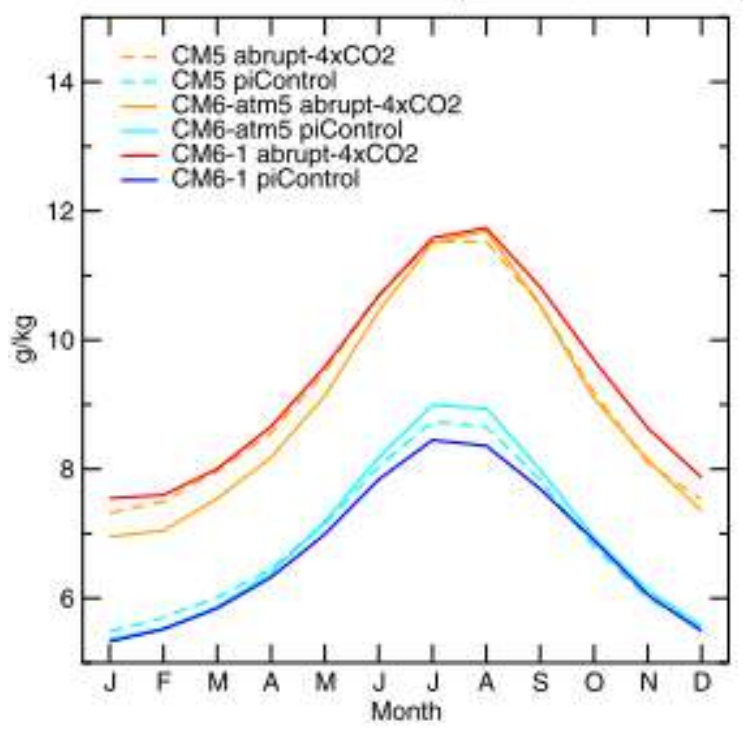

(b) Climatological annual cycle of $\mathrm{RH}$ over Global Ocean [90S-90N, 180W-180E]

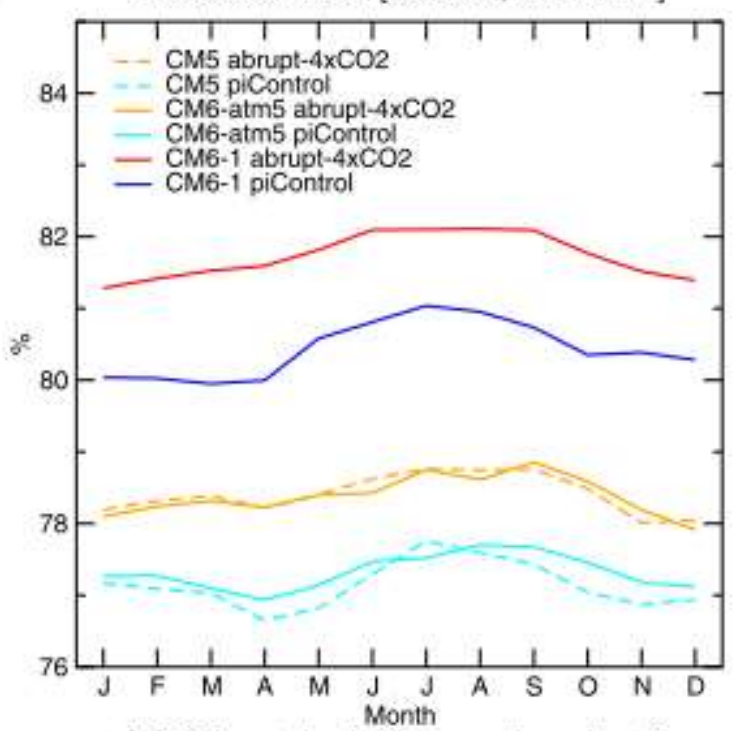

(d) Climatological annual cycle of $q$ over Global Ocean [90S-90N,180W-180E]

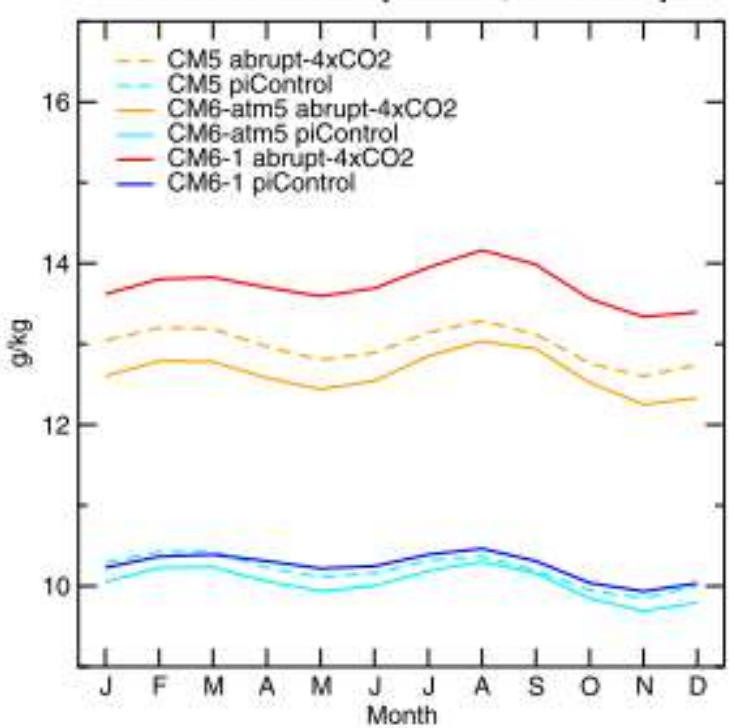

Figure 3 


\section{JJAS mean RH scaled response to abrupt4xCO2}
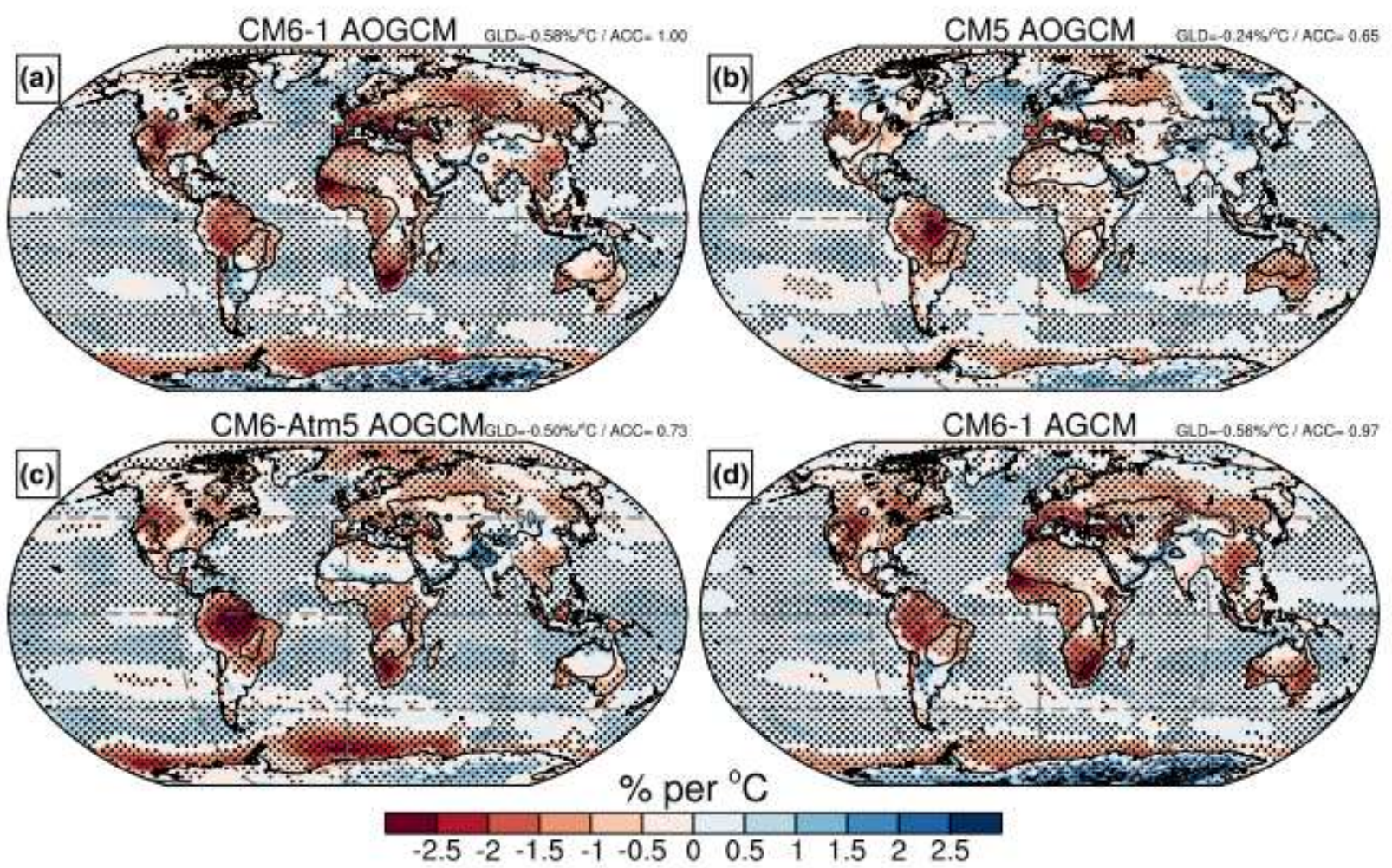

Figure 4 


\section{AGCM breakdown of JJAS RH anomalies from CNRM-CM6-1}
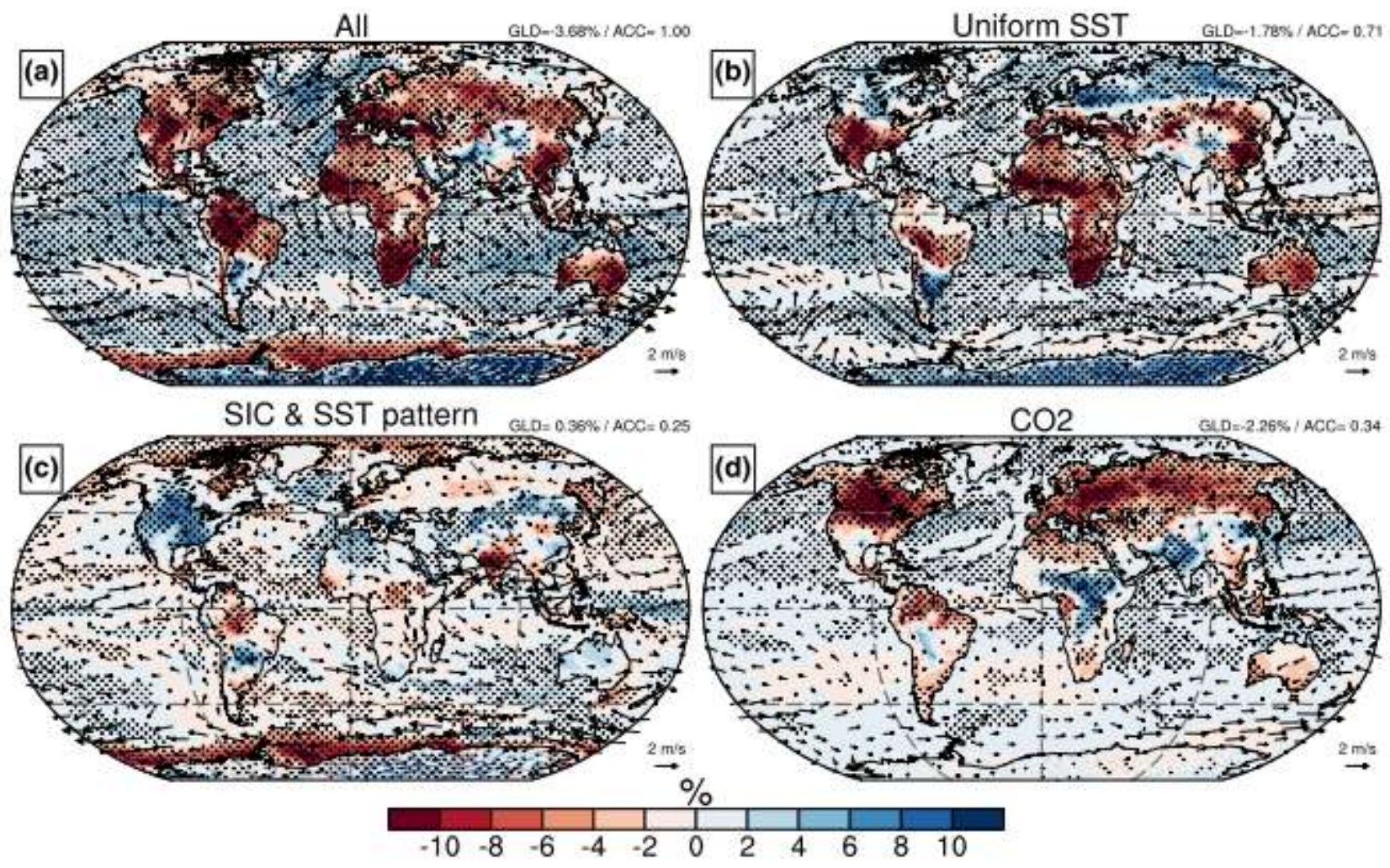

695

Figure 5 
AGCM breakdown of JJAS RH anomalies from CNRM-CM5

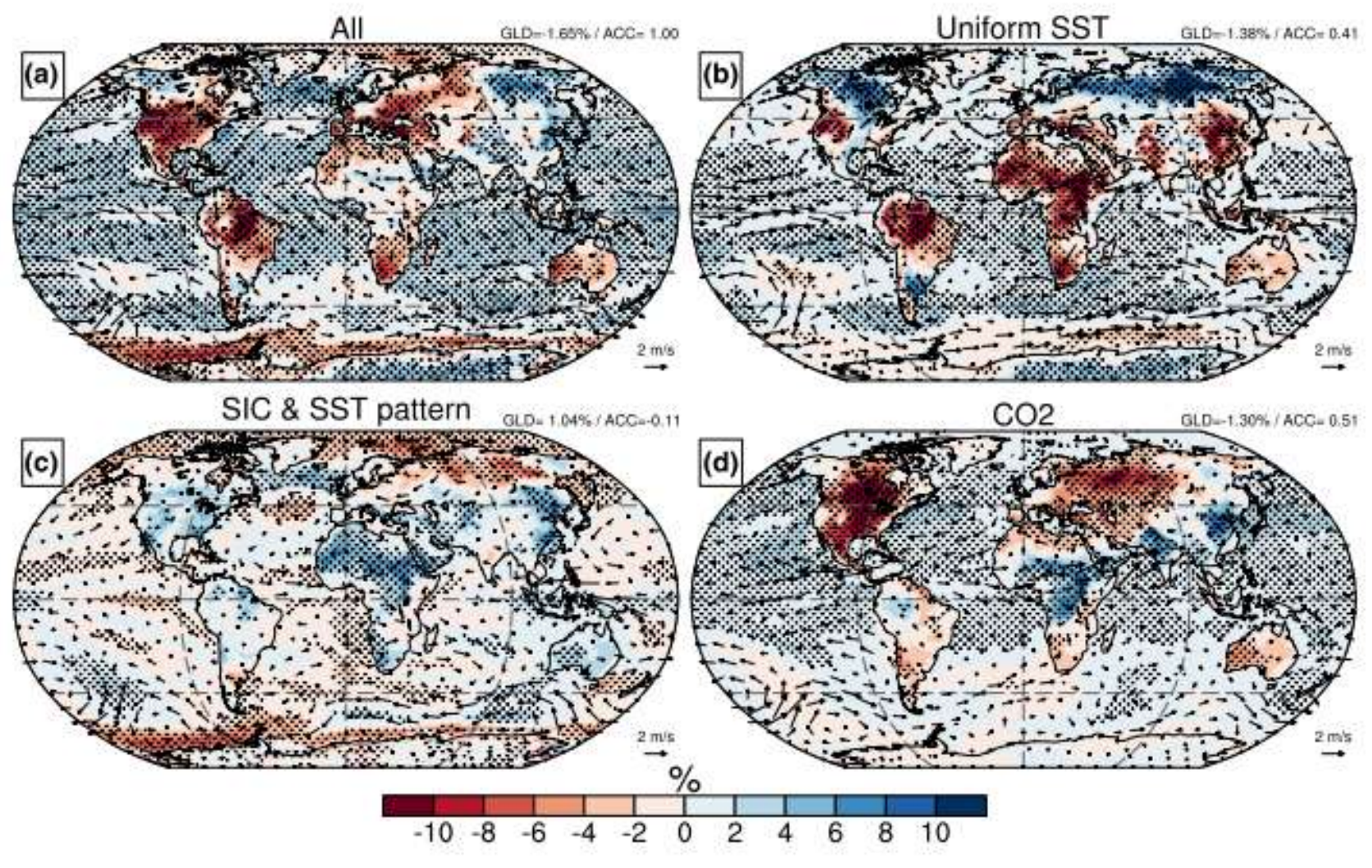

Figure 6 


\section{Breakdown of $\mathrm{CO} 2$ effect on JJAS RH in CNRM-CM6-1}
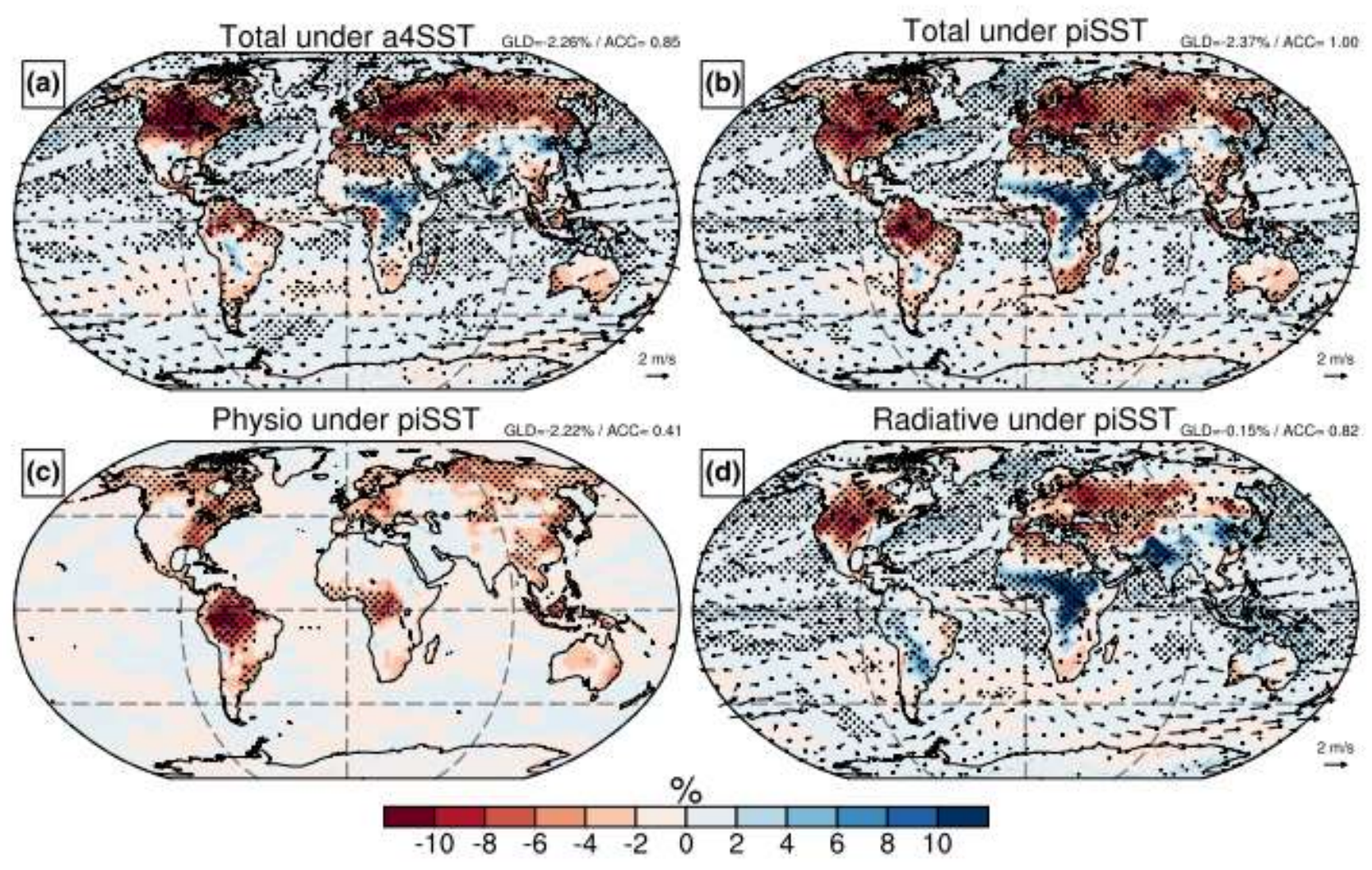

Figure 7 
Changes in JJAS mean Qair
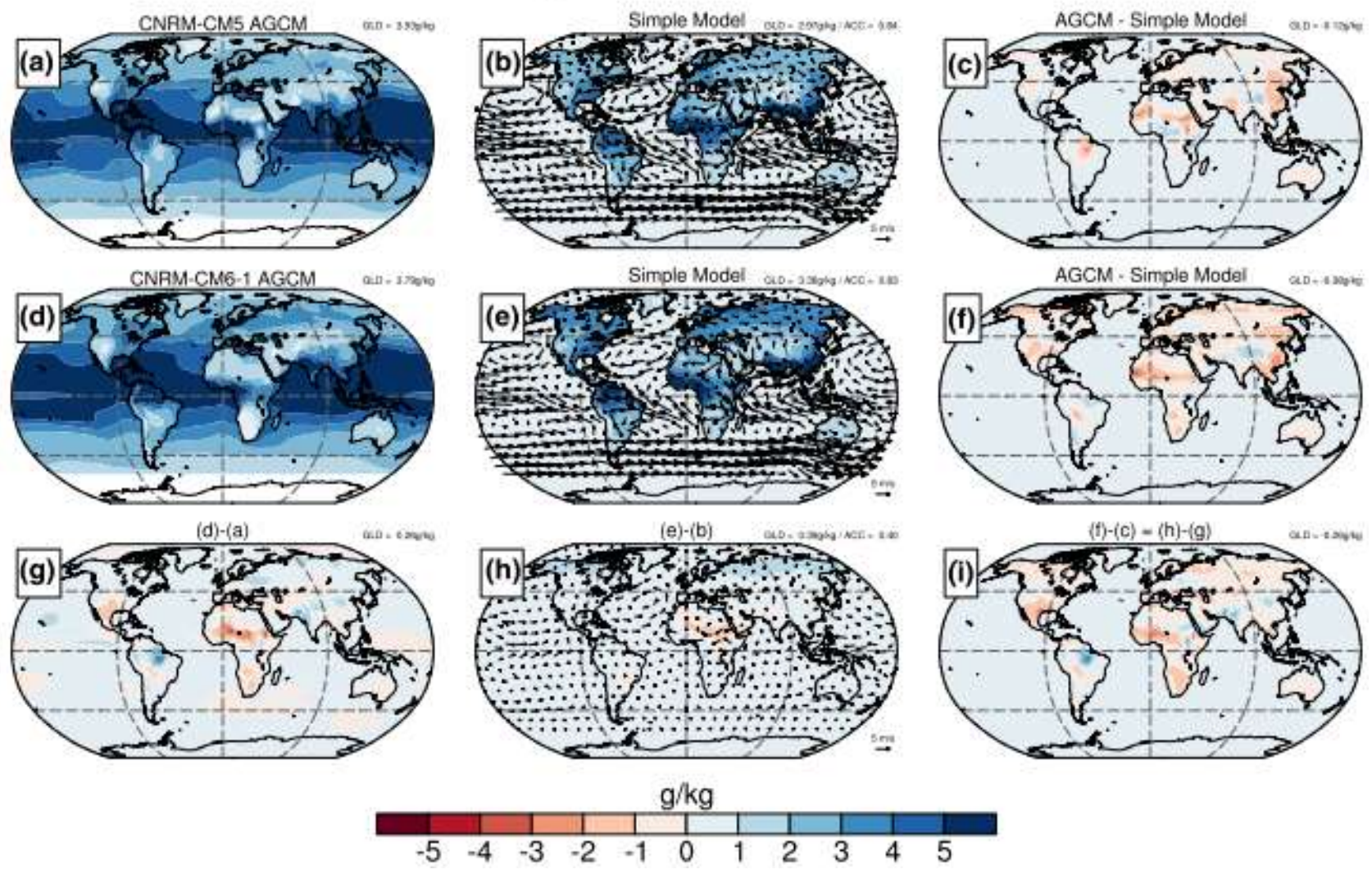

Figure 8 
Changes in JJAS mean RH

CNAM-CNS AGCM
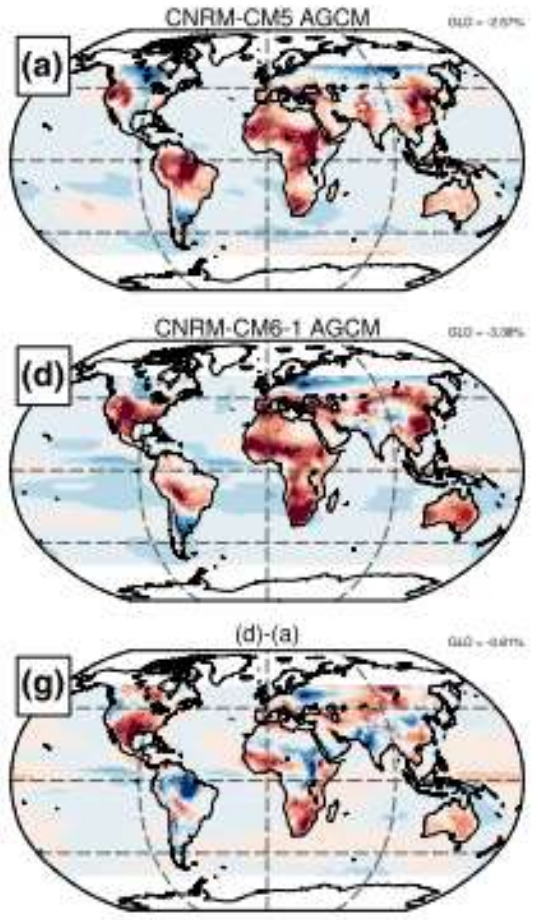

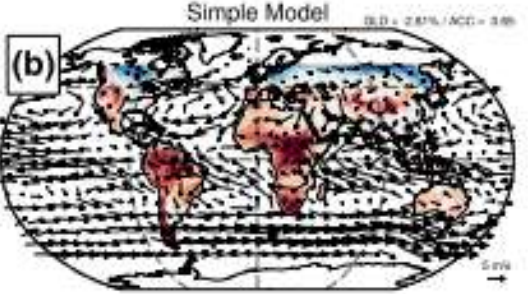

Simple Model

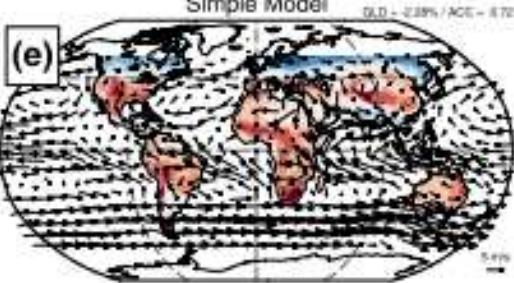

(e)-(b)

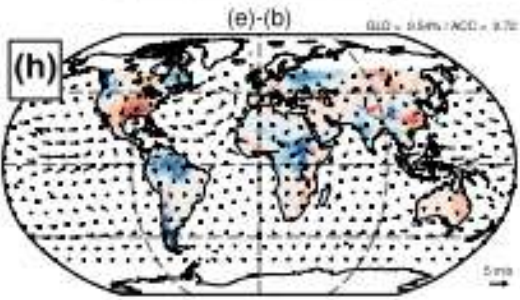

AGCM - Simple Mode

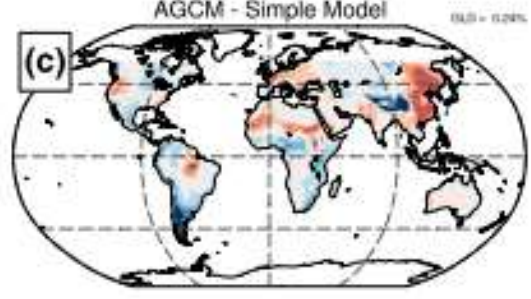

AGCM - Simple Mode

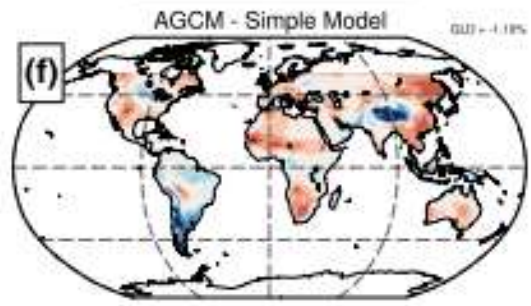

(f)- (c) $=(\mathrm{h})-(\mathrm{g})$

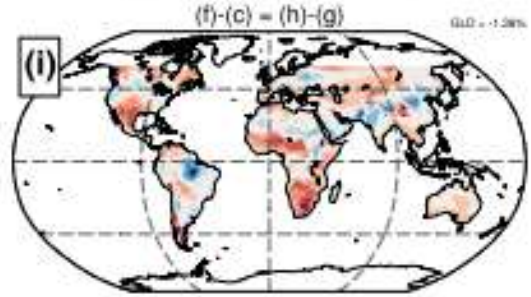

Figure 9 
Base state effect on JJAS RH anomalies (\%)

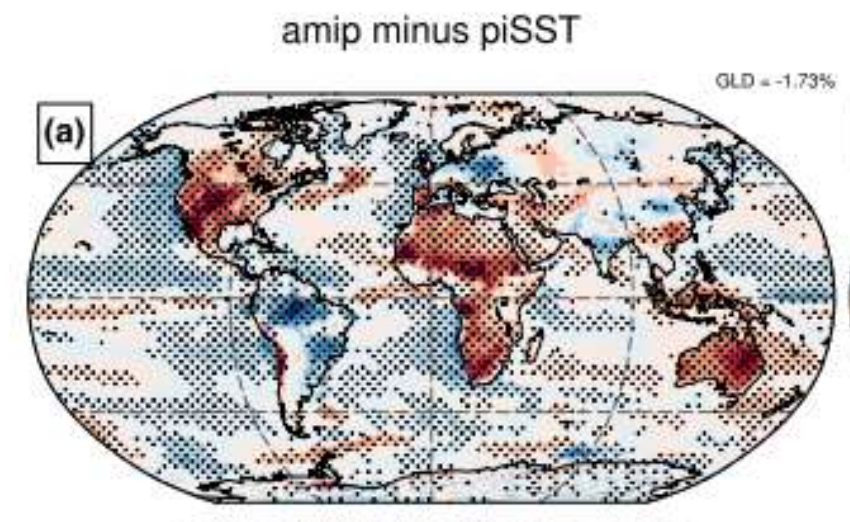

amip-a4SST-4xCO2 minus a4SST-4xCO2

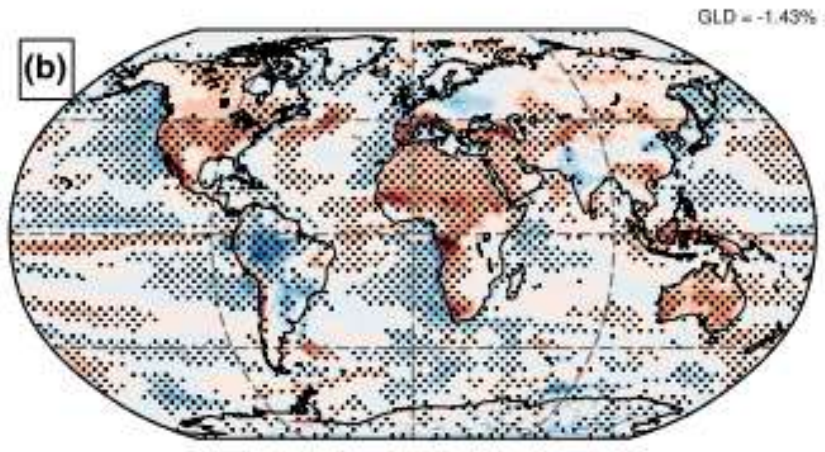

amip-a4SST-4xCO2 minus amip

a4SST-4xCO2 minus piSST

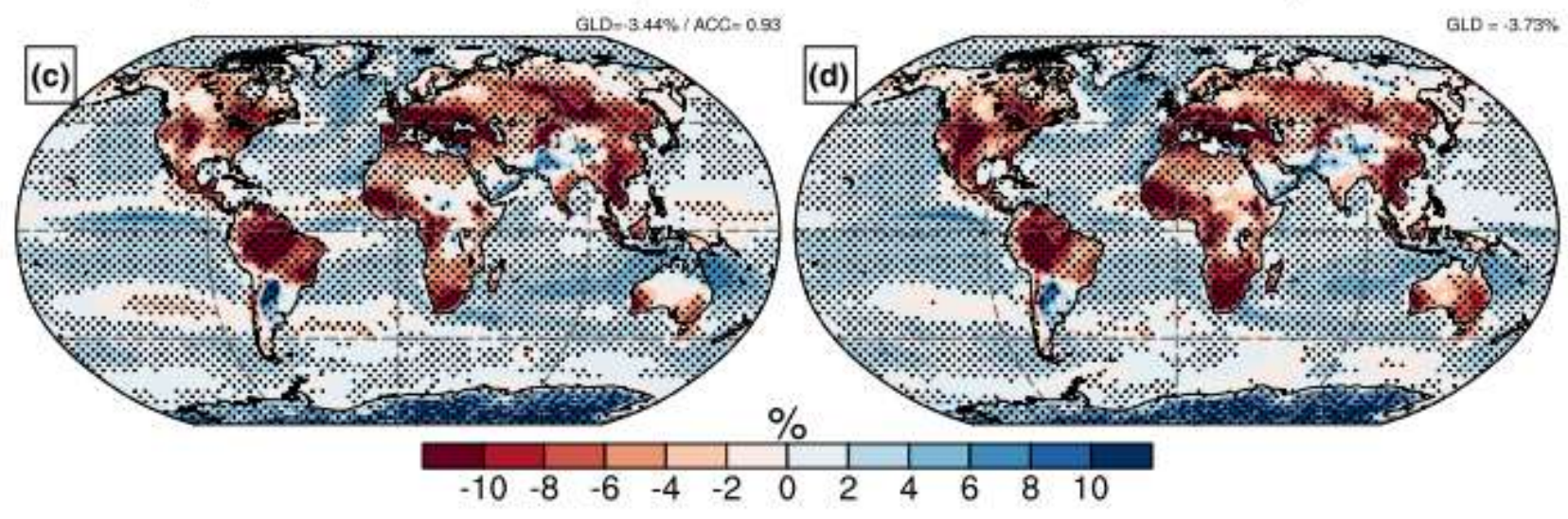


Linearity to increased $\mathrm{CO} 2$
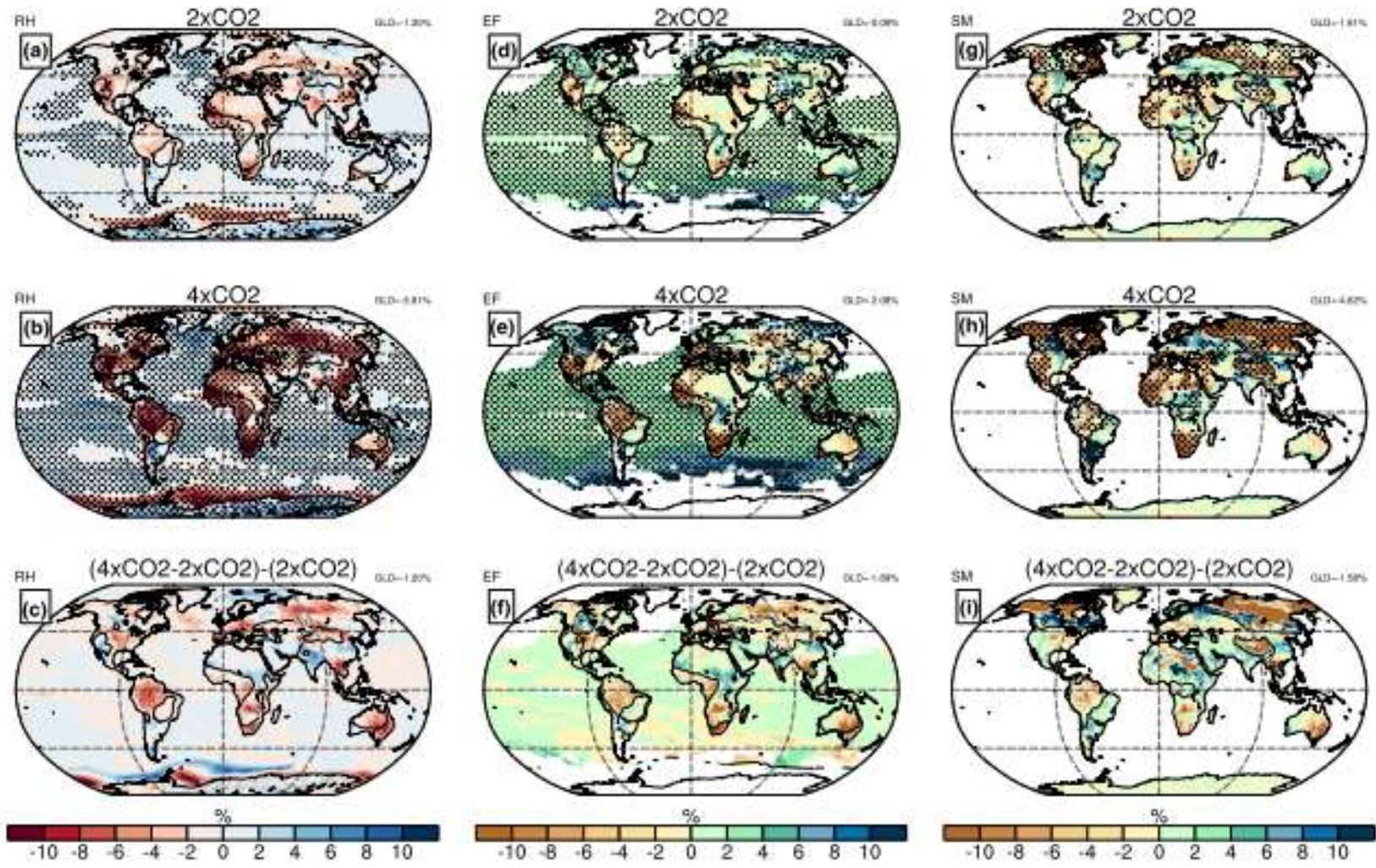

Figure 11 